\title{
El parque del Buen Retiro de Madrid: valor patrimonial y uso ciudadano y turístico
}

\author{
María Pilar Palomar Anguas* \\ Universidad Rey Juan Carlos (España)
}

\author{
Daya Morales Jaime**
}

Investigadora independiente

\begin{abstract}
Resumen: Tras la exposición de los objetivos y metodología, se realiza un comentario sobre la preservación del patrimonio en España, en particular de El Retiro, así como de la reciente presentación de la candidatura "Paseo del Prado y el Retiro. Paisaje de las Artes y las Ciencias" a la lista del Patrimonio Mundial de la UNESCO. La evolución de El Retiro ha ido de la mano de su desarrollo como Real Sitio. La descripción de su patrimonio permite conocer detalles de su historia hasta la actualidad, que ha configurado un magnífico entorno de gran exotismo en el corazón de Madrid. El análisis de los recursos y de la actividad turística y cultural que soporta, junto con los resultados de una encuesta realizada a los visitantes, evidencian su gran aceptación por parte de residentes y turistas; también la existencia de problemas en la gestión e información dirigida al público, que respectivamente repercuten en el mantenimiento y aprovechamiento de este espacio singular.
\end{abstract}

Palabras Clave: Parque de El Retiro; Patrimonio Mundial; Jardín Histórico; Bien de Interés Cultural (BIC); Turismo.

\section{The Buen Retiro Park in Madrid: heritage value and citizen and tourist use}

Abstract: After outlining the objectives, methodology and making brief allusion to concepts and laws in relation to the preservation of heritage in Spain, and the recent presentation of the candidacy "Paseo del Prado $y$ el Retiro. Landscape of the Arts and Sciences" to the UNESCO World Heritage list, the article goes on to give a brief historical description of the evolution of the Retiro Park, since its origins, as a highly exotic Royalty Site in the heart of Madrid. An analysis of the park'sresources and the tourist and cultural activity offered in El Retiro is given together with the results of a survey carried out among visitors, showing the great acceptance of the site by residents and tourists alike but also highlighting the existence of certain management and information problems iwhich respectively affect the maintenance and use of this unique space.

Keywords: El Retiro Park; World Heritage; Historical Garden; Cultural Interest Asset (BIC); Tourism.

\section{Introducción. Objetivos, metodología y contexto.}

Este trabajo tiene, entre otros objetivos, ilustrar sobre el patrimonio cultural y la larga historia del Parque del Buen Retiro, para lo cual se detallan los bienes patrimoniales más importantes y se describe algunos de ellos, así como los momentos destacables de su larga historia. Para ello se ha realizado una revisión documental con la que se intenta trascender su valoración como mero parque de ocio de cara a la mayor parte de la ciudadanía y visitantes. Aunque dicha estimación no debe ser desdeñable, si es deseable un mayor conocimiento y disfrute de los bienes patrimoniales, en su momento creados por la corte para su disfrute exclusivo.

Tras la presentación de este patrimonio, el trabajo se dirige hacia otros objetivos como son: el análisis de la gestión y mantenimiento del parque; el nivel de conocimiento y valoración de la ciudadanía y otros

\footnotetext{
Universidad Rey Juan Carlos (España); Membro dos grupos de pesquisa TADAT (URJC) e GIGATU (PUCP); Email: pilar. palomar@urjc.es; https://orcid.org/0000-0003-1615-0858

** Investigadora independiente; E-mail: dayamoralesj@gmail.com; https://orcid.org/0000-0001-8146-7187
} 
visitantes del patrimonio natural y cultural del parque; el conocimiento de los recursos patrimoniales más atractivos para los usuarios y, por último, la delimitación de áreas del parque en función de los flujos de los visitantes para su uso turístico o de ocio ciudadano.

$\mathrm{El}$ análisis de la gestión y mantenimiento del parque se realiza gracias a la información aportada por la segunda de las coautoras, derivada de su propia experiencia de trabajo en el Palacio de Cristal, y de las entrevistas y encuestas realizadas a trabajadores ${ }^{1}$ del parque y a visitantes ${ }^{2}$, respectivamente. A lo anterior se añade la observación de campo de los flujos de visitantes.

Dichas entrevistas y la información documental permiten esbozar los problemas que ha de afrontar el mantenimiento del patrimonio, especialmente el natural. Por otro lado, y gracias a las encuestas a visitantes y al contacto directo con ellos, se ha podido evaluar su nivel de conocimiento del patrimonio y de los recursos turísticos disponibles, así como su valoración y uso real de los mismos.

La valoración del patrimonio por la sociedad y sus instituciones ha crecido a lo largo del siglo anterior, pese a los tremendos desastres sufridos por aquel con las dos guerras mundiales. Afortunadamente y finalizada la segunda de ellas la protección del patrimonio y de la cultura fue un deseo urgente que, en 1945, dio paso a la creación de la Organización de las Naciones Unidas para la Educación, la Ciencia y la Cultura (UNESCO) y, ya en 1972, a la Convención que establecía las pautas para dicha protección.

En España, pese a la tardía ratificación de dicha convención, en 1982, y la inscripción en 1984 de los primeros bienes en la lista del Patrimonio Mundial ${ }^{3}$, el interés por la salvaguardia del patrimonio, expresado en la legislación, se remonta a la primera mitad del siglo diecinueve (Palomar, 2019), como consecuencia de las desamortizaciones de José Bonaparte (1809) y de Mendizabal (1836). Posteriormente nuestro patrimonio ha pasado por numerosas vicisitudes físicas y legales, como fue la alternancia entre los gobiernos republicanos y las restauraciones monárquicas. No obstante, el parque de El Retiro, objetivo de este trabajo, ha permanecido como bien público ${ }^{4}$ desde 1868, gozando de protección desde $1935^{5}$, merced a su declaración como Jardín Histórico o Artístico en dicho año y a su calificación en $1985^{6}$ como Bien de Interés Cultural (BIC) en la categoría de Jardín Histórico.

Un hito importante en esta línea de pensamiento, ha sido la presentación de la Candidatura para formar parte de la lista del Patrimonio Mundial de la UNESCO de la totalidad del parque del Buen Retiro y su entorno museístico y monumental.

\section{La candidatura a la lista del Patrimonio Mundial de la UNESCO: "Paseo del Prado y el Retiro. Paisaje de las Artes y las Ciencias".}

El Parque de El Retiro ha sido promovido a la lista de Patrimonio Mundial de la UNESCO a través del Consejo de Patrimonio Histórico, que el pasado año presentó la candidatura: "Paseo del Prado y El Retiro. Paisaje de las Artes y las Ciencias"'. El proyecto involucra grupos, organizaciones, instituciones y comunidades a todos los niveles, buscando un carácter participativo e innovador. Entre ellas la Real Academia Española, la Bolsa de Comercio, el Palacio de Fomento (hoy Ministerio de Agricultura), el Cuartel General de la Armada y Museo Naval, la Iglesia de los Jerónimos y la Asociación de los Amigos del Buen Retiro. De igual manera, están integradas las tres administraciones ${ }^{8}$ y los partidos políticos con representación municipal.

La candidatura plantea el valor universal y excepcional de este bien patrimonial por la unión en el mismo entre naturaleza, cultura y ciencia. La UNESCO podrá considerar y valorar los extraordinarios elementos paisajísticos y arquitectónicos que han resultado de su evolución, desde su origen como Real Sitio y escenario del Siglo de Oro español, hasta su completa integración en el corazón del Madrid de hoy. Un reconocimiento que significaría una puesta en valor ante la comunidad internacional, una concienciación ciudadana de su importancia histórica, cultural y natural y, también una contribución a su conservación.

Los espacios incluidos en la candidatura (Fig. 1) comprenden el eje del Paseo del Prado y el barrio de los Jerónimos, con más de una veintena de edificios monumentales, algunos de los cuales albergan grandes pinacotecas. También fuentes y rotondas emblemáticas, como la Fuente de la Cibeles y la Puerta de Alcalá, en la Plaza de la Independencia, situándose en ésta la entrada principal de El Retiro, que se extiende hasta las inmediaciones de la estación de Atocha, una férrea y bella estructura también incluida en la candidatura. 
Figura 1: Recinto del espacio incluido en la Candidatura a la UNESCO

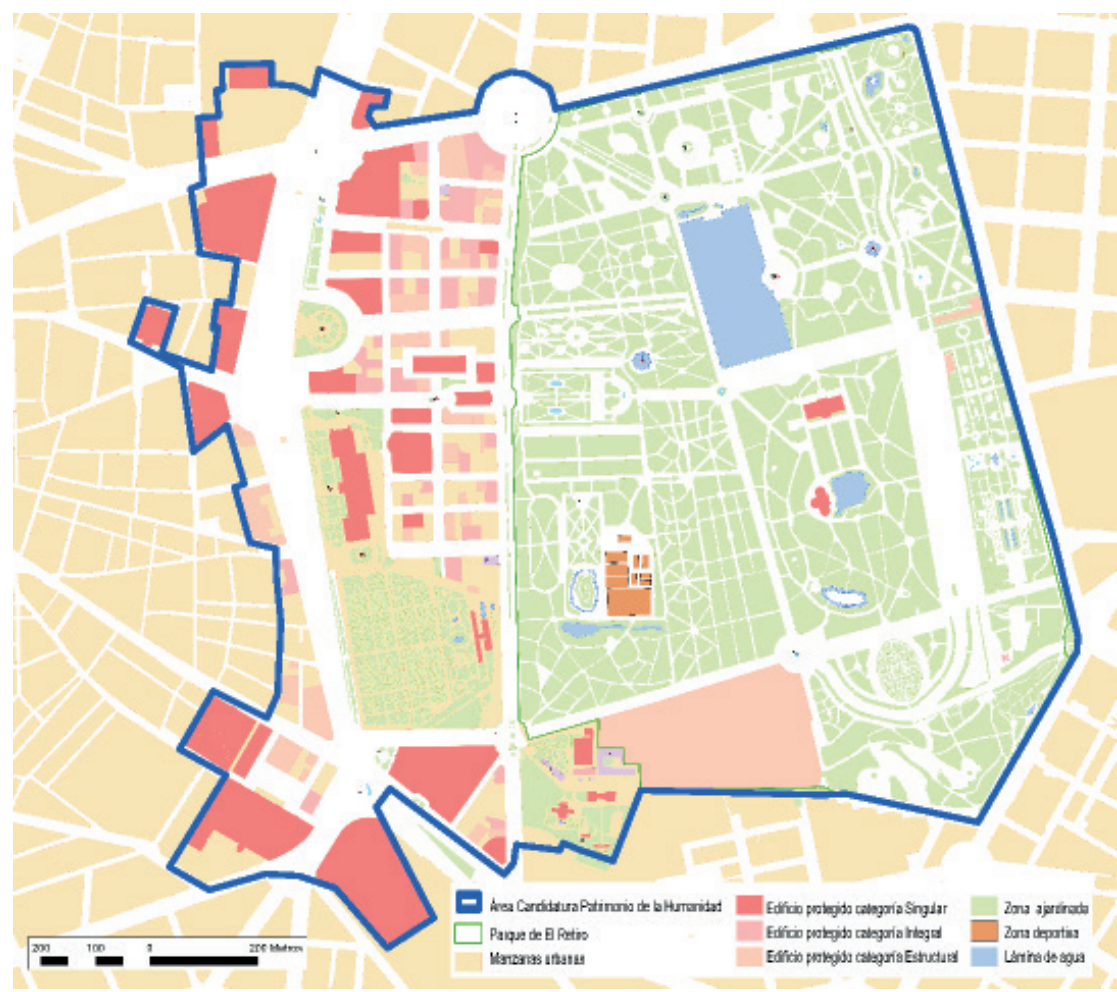

Fuente: Elaboración propia.

\section{El Retiro: Testigo de la historia de Madrid}

En su origen fue un espacio boscoso con recursos hídricos ${ }^{9}$, que propiciaron la reubicación en el mismo del Monasterio e Iglesia de los Jerónimos ${ }^{10}$. Este fue el germen del Real Sitio de El Retiro y de todas las edificaciones monumentales y obras de reforestación o de ajardinamiento - en especial realizadas en los siglos XVII y XVIII - que fueron ocupando la suave ladera situada al este del arroyo de la Castellana, del Prado o del Carcavón (Domínguez, 2019), que venía a ser el límite oriental del Madrid de los Austrias. En definitiva, la ubicación de El Retiro es una consecuencia del traslado de aquel monasterio y su reedificación en los primeros años del siglo XVI.

Junto al Monasterio, Felipe II ordenó la construcción del "cuarto real" o cuarto de San Jerónimo, que comprendía un número reducido de estancias utilizadas por la realeza como lugar de descanso o retiro ocasional, especialmente en Cuaresma; también como lugar de recepción de visitantes notables a la reciente capital que vino a ser Madrid.

En 1629, por iniciativa y con la tenacidad del Conde Duque de Olivares, Felipe IV inició el desarrollo de un vasto proyecto que culminó con la edificación del palacio en solo tres años (Fig. 2). Éste presentaba un cuerpo principal de estilo herreriano, con un gran patio central y torres en sus esquinas, similar al Monasterio de Escorial, pero en este caso con materiales menos duraderos (ladrillo y madera) y una ejecución muy apresurada. La austeridad y escasa vistosidad del edificio contrastaba con su interior, repleto de obras de arte (pintura, escultura, muebles y objetos diversos) creadas en España durante "el siglo de oro español", y también traídas de otros países europeos, merced a las apremiantes gestiones del mismo Conde Duque (Brown y Elliot, 2016).

El recinto palaciego también albergó el Coliseo del Buen Retiro, espacio de representaciones teatrales y operísticas para la corte, asimismo abierto al público, que pudo asistir a las grandes obras teatrales del siglo de oro. No en vano Calderón de la Barca fue nombrado su director (Flórez, 1998). 


\section{Figura 2: Vista del Palacio y Jardines del Buen Retiro (1637). Atribuido a Jusepe Leonardo.}

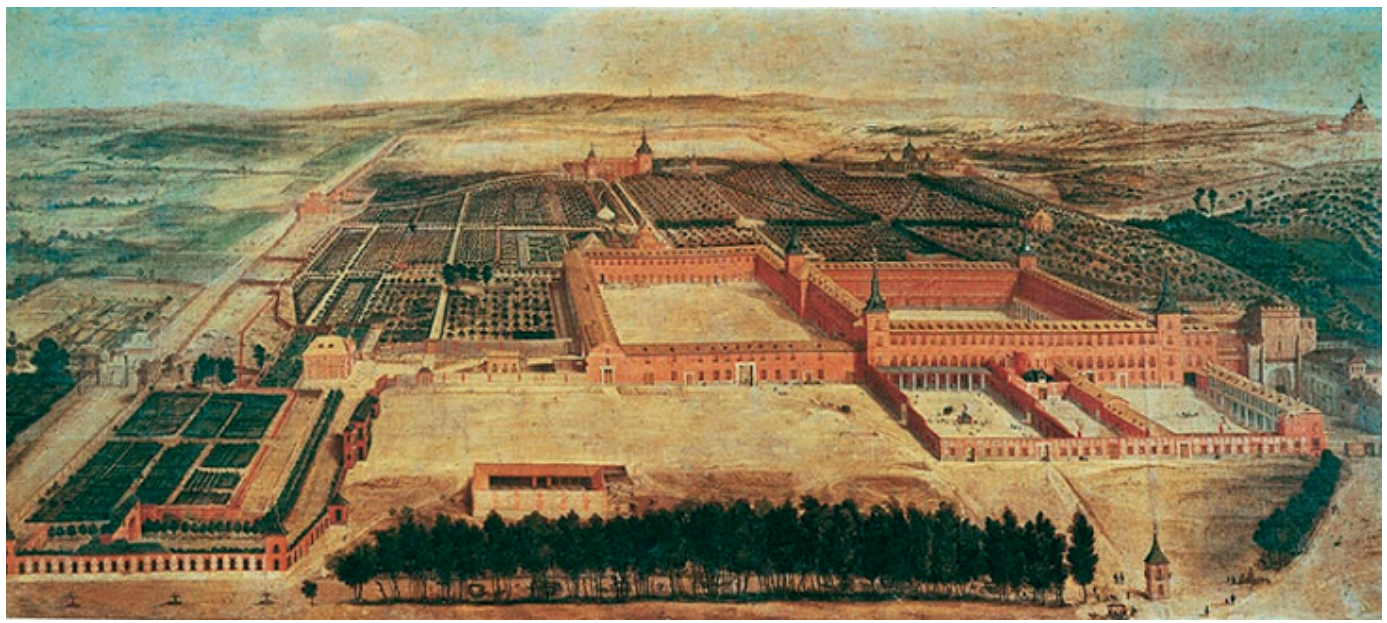

Fuente: Patrimonio Nacional.

Paralelamente, los exteriores del palacio fueron objeto de ajardinamiento, con especial protagonismo del agua en el diseño de estanques, canales y fuentes para el recreo y descanso de la realeza y la corte. Estos espacios verdes fueron escenario de representaciones teatrales, fuegos artificiales, cacerías, corridas de toros, luchas entre fieras y paseos en góndola (Durán, 2002).

El Real Sitio de El Buen Retiro, así creado en el lado oriental de la ciudad, coexistió hasta el siglo XIX con las antiguas propiedades reales situadas en el lado occidental: Palacio Real, jardines anejos y Casa de Campo, a las que, a finales del siglo XVIII, se añadió la Real Posesión de La Florida (fig. 3).

Figura 3: Plano de Madrid de 1762. Escala 1:31.000.

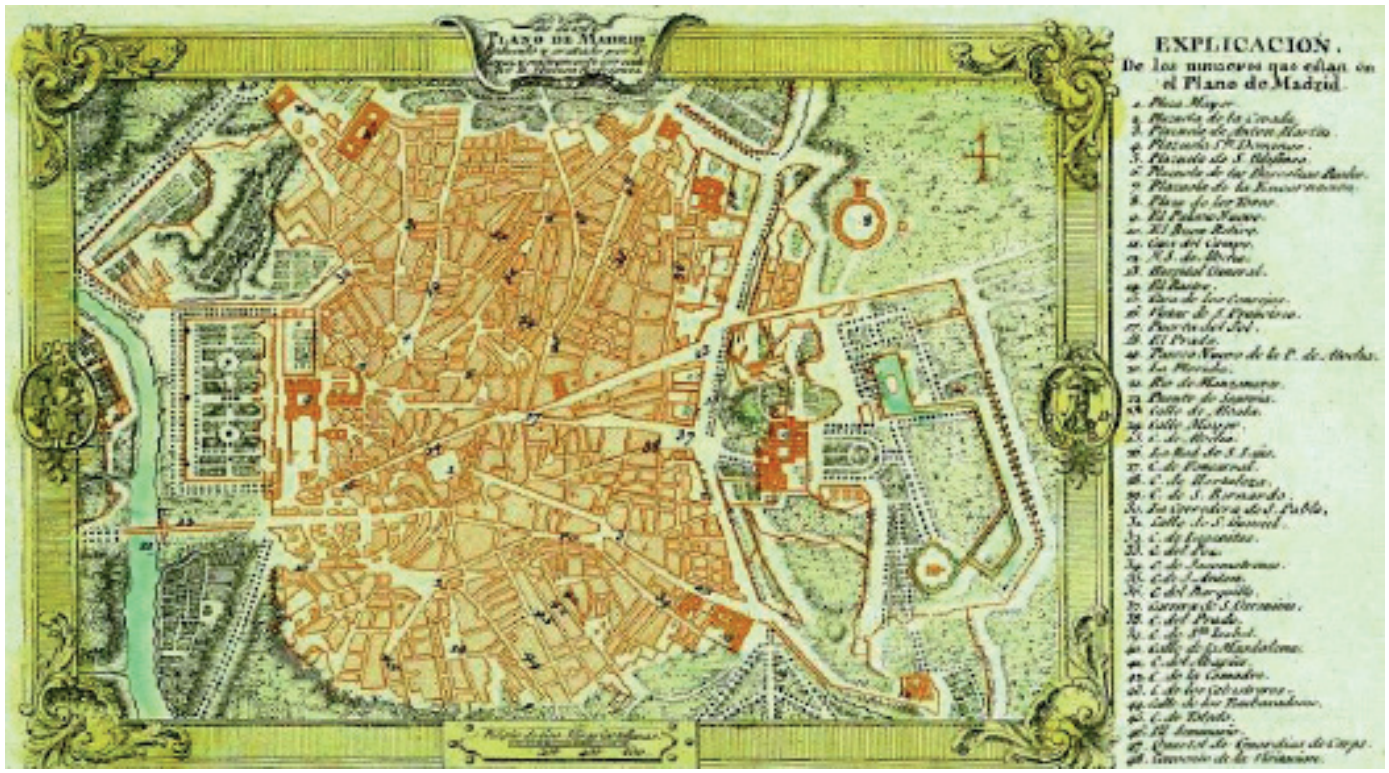

Fuente: Real Academia de la Historia. 
Con la dinastía borbónica (Felipe V, Fernando VI, Carlos III y Carlos IV), hasta la invasión francesa y la consiguiente guerra de la independencia (1808-1814), el espacio actualmente comprendido en la candidatura presentada a la UNESCO, fue adquiriendo nuevos edificios y monumentos propios de la época de la Ilustración, siendo Carlos III el artífice principal de esta etapa. Tales son el Real Estudio de Historia Natural (actual edificio principal del Museo del Prado), el Real Observatorio Astronómico y las emblemáticas fuentes de Cibeles, Neptuno, Apolo y las Fuentecillas, todo ello posterior al Jardín Botánico y a la Real Fábrica de Cerámica (Fig.4).

Figura 4: Fragmento del Plano geométrico de Madrid, 1785, correspondiente al Real Sitio de El Retiro

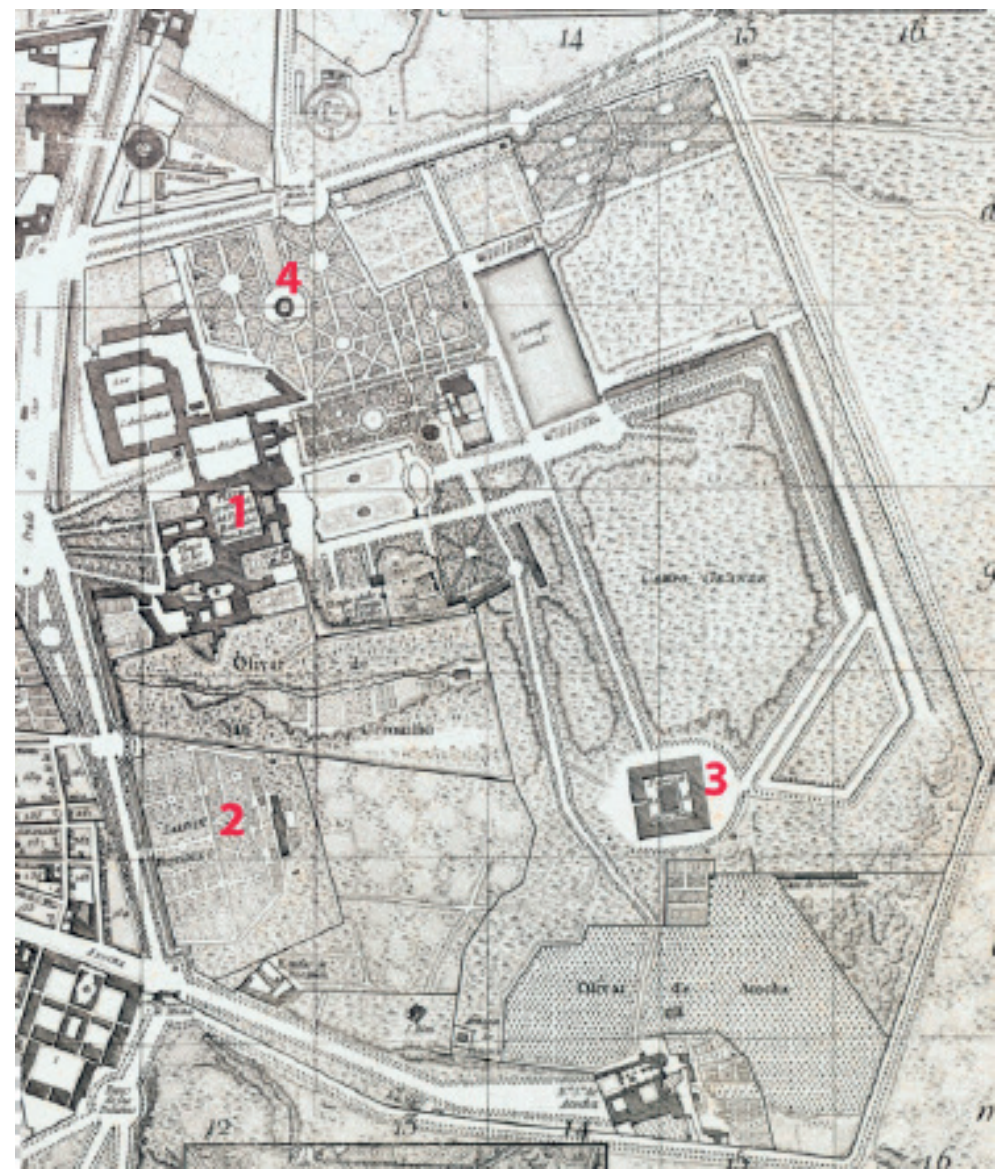

Autor: López de Vargas Machuca. Tomás. 1: Complejo palaciego; 2: Jardín Botánico; 3: Real Fábrica de Cerámicas; 4: La Leonera.

Tras la guerra de independencia y la ocupación de El Retiro como cuartel general por el ejército francés, el palacio de los Austrias quedó prácticamente destruido ${ }^{11}$ y en situación de abandono, en tanto que sus exteriores fueron objeto de importantes restauraciones que cambiaría definitivamente su configuración. Fernando VII realizó "el reservado", con sus extravagantes "caprichos". Lo más conocido de sus incorporaciones al parque fue la Casa de Fieras ${ }^{12}$, en 1830 (Aparisi, 2011a), que fue el "zoo" madrileño hasta su traslado, en 1977, al actual emplazamiento en Batán (Casa de Campo).

Con Isabel II se produjo la intervención más decisiva en el entorno de las ruinas del palacio, con la venta en 1865 y posterior urbanización de todo el espacio situado al norte del jardín botánico hasta la 
calle de Alcalá, hoy barrio de los Jerónimos. Con esta intervención quedó definido el límite occidental de El Retiro a lo largo de la calle Alfonso XII, entre la Puerta de Alcalá y la Estación de Atocha (Fig. 5).

Como se ha visto anteriormente, en 1868 El Retiro se convierte en un espacio de recreo para los madrileños. Pero también fuente de problemas y desencuentros entre la gestión y gestores municipales del mismos y los funcionarios de Patrimonio de la Corona, todavía propietaria de los bienes del parque. Sirve de ejemplo el traslado, por parte de Patrimonio, de los animales alojados en la Casa de Fieras a la Casa de Campo, que posteriormente fueron devueltos. En estas idas y vueltas algunos ejemplares desaparecieron (Cayetano, 2011)

Las modificaciones e incorporaciones posteriores al propio recinto del parque han ido enriqueciendo su patrimonio natural y cultural hasta fechas recientes; un patrimonio, que descrito con brevedad, permite conocer algo más sobre la historia del propio parque hasta la actualidad ${ }^{13}$.

\section{Figura 5: Trabajos del Plano de Madrid. Distrito del Congreso: Parque del Retiro, Jardín Botánico y Paseo del Prado. 1910. Escala 1:4.000}

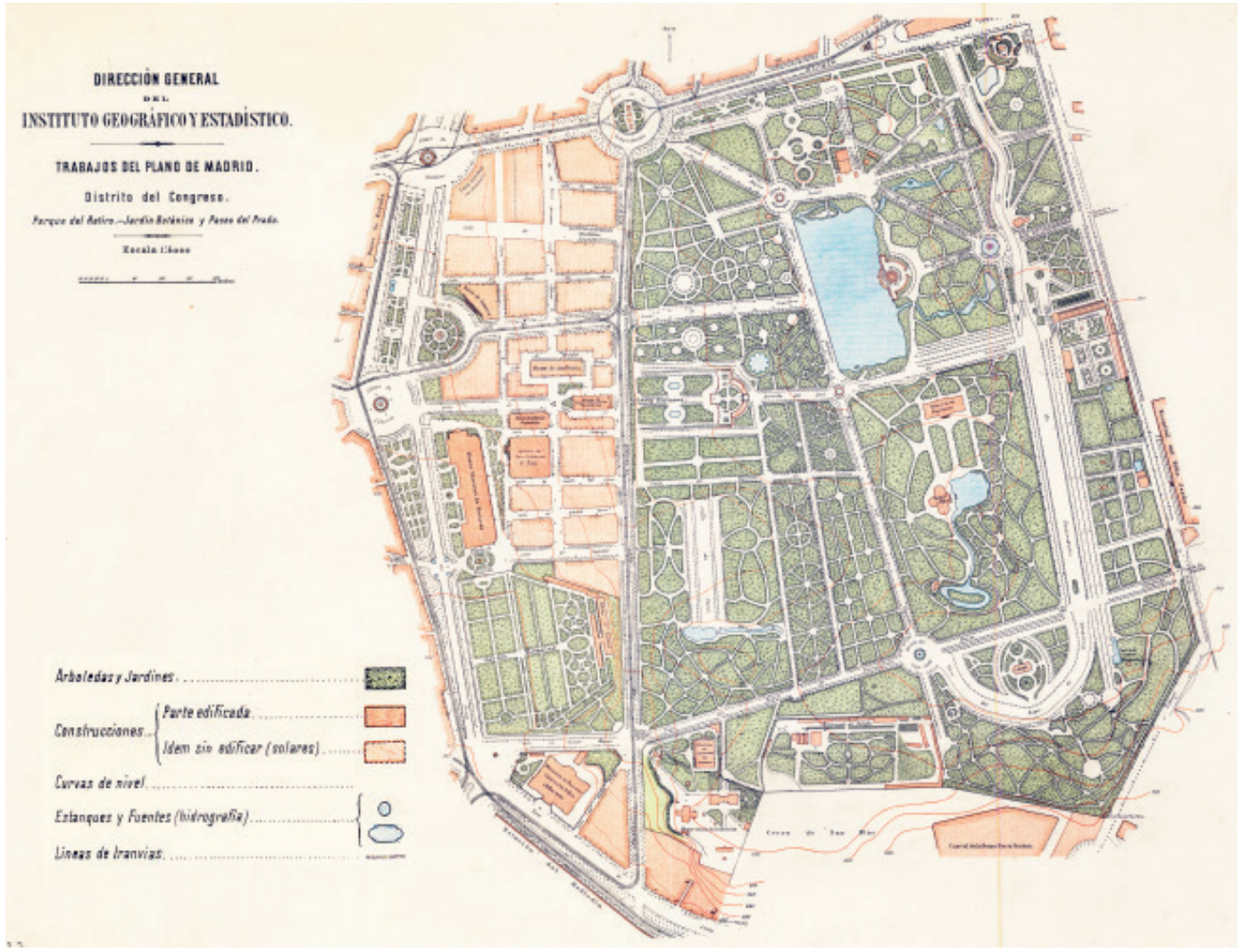

Fuente: Dirección General del Instituto Geográfico y Estadístico.

\section{Recursos Patrimoniales de El Retiro}

El Retiro ha sufrido grandes modificaciones a lo largo del tiempo, y algunos de sus elementos patrimoniales han desaparecido o han sido transformados. Lo que permanece se caracteriza por la imbricación entre elementos naturales, arquitectónicos y de ornato, que han seguido una evolución simultánea e interdependiente, puesto que la ordenación del espacio para su ajardinamiento en muchos casos fue acompañada de edificaciones, esculturas, fuentes, etc. Todo ello de acuerdo con los 
gustos de cada época, en ocasiones superponiéndose unos a otros mediante modificaciones, traslados y nuevas incorporaciones de elementos patrimoniales. Se revisan así los recursos naturales y materiales que perduran; su descripción resumida aporta más detalles de la historia ligada al parque, algunos anecdóticos, otros de mayor calado.

\subsection{Jardines y zonas verdes.}

La masa verde de El Retiro limpia la contaminación ambiental (Gómez-Moreno et al. 2019) y atenúan la temperatura de su interior y en el entorno más próximo de la ciudad (Aram et al. 2019). Constituye un pulmón incrustado en el casco urbano de la ciudad, con $570.000 \mathrm{~m}^{2}$ de zona ajardinada y 17.508 árboles, localizados en su mayoría sobre césped o praderas naturales. De las 163 especies catalogadas, el castaño de Indias (Aesculus hippocastanum) es la más abundante, alcanzando el 34,32\% del número de ejemplares. El plátano de sombra (Platanus x hybrida) y el árbol del amor (Cercis siliquastrum) suponen el 5,3\% y 4,2\% del arbolado respectivamente. Otras especies destacadas por su importante presencia son: la palmera excelsa (Trachycarpus fortunei), el ciprés mediterráneo (Cupressus sempervirens), el almez (Celtis australis), la acacia de tres espinas (Gleditsia triacanthos), el pino piñonero (Pinus pinea), la acacia del Japón (Sophora japónica) y el olmo de Siberia (Ulmus pumila), cuya abundancia oscila entre el 3,5\% la primera y 2,26\% las dos últimas (Ayuntamiento de Madrid, 2019a).

La gran diversidad del arbolado del parque es la lógica consecuencia de su larga historia. Se han identificado 923 árboles con elevado interés histórico o paisajístico, que equivalen al 5\% del total (Ayuntamiento de Madrid, 2016a). Ocho de ellos están catalogados como árboles singulares (Decreto 18/1992, de 26 de marzo; Orden 68/2015, de 20 de enero) (Tabla 1 y Fig. 6).

Tabla 1: Árboles singulares de El Retiro

\begin{tabular}{|c|c|c|c|}
\hline & Nombre común & Nombre cientifico & Localización \\
\hline 1 & Ahuehuete del Parterre & Taxodium mucronatum & Parterre del parque de El Retiro \\
\hline 2 & $\begin{array}{l}\text { Arce Plateado de los Jardines de Cecilio } \\
\text { Rodríguez }\end{array}$ & Acer saccharinum & Jardines de Cecilio Rodríguez \\
\hline 3 & Cedro del Parque de El Retiro & Cedrus libanotica & $\begin{array}{l}\text { Antiguo Reservado, cerca monumento } \\
\text { General Martinez Campos, }\end{array}$ \\
\hline 4 & $\begin{array}{l}\text { Ciprés Calvo del Estanque del Palacio } \\
\text { de Cristal }\end{array}$ & Taxodium distichum & $\begin{array}{l}\text { Campo Grande, en el Estanque del } \\
\text { Palacio de Cristal }\end{array}$ \\
\hline 5 & Palmera de Fortune de El Retiro & Trachycarpus fortunei & $\begin{array}{l}\text { Campo Grande, cerca de la ría de } \\
\text { patinar }\end{array}$ \\
\hline 6 & $\begin{array}{l}\text { Pino Carrasco de la Rosaleda de El } \\
\text { Retiro }\end{array}$ & Pinus halepensis & Rosaleda de El Retiro \\
\hline 7 & Eucalipto azul del Retiro & Eucaliptus globulus & $\begin{array}{l}\text { Antiguo Reservado, entre el } \\
\text { embarcadero y el Paseo de Coches }\end{array}$ \\
\hline 8 & Tejo del Palacio de Velázquez del Retiro & Taxus baccata & $\begin{array}{l}\text { Campo Grande, próximo al Palacio de } \\
\text { Velázquez del Retiro }\end{array}$ \\
\hline
\end{tabular}

Fuente: elaboración propia a partir de Comunidad de Madrid, 2013 y Orden 68/2015, de 20 de enero. 
Figura 6: Ahuehuete. Catalogado como Árbol Singular

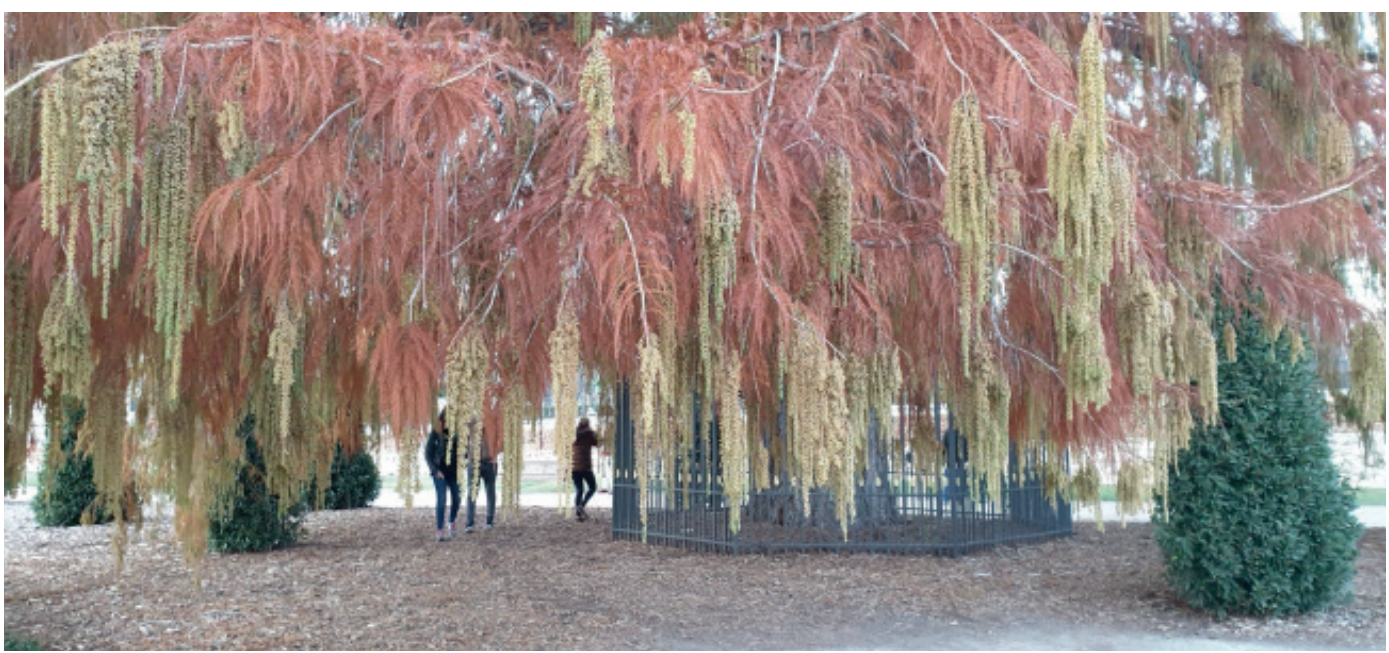

Fuente: Elaboración propia.

El parque de El Retiro carece de un orden en torno a un eje principal y obedece a una yuxtaposición de recuadros de arbolados y jardines contiguos, pero a la vez independientes, con diferentes diseños que se han ido transformando según los gustos de cada época (Fig. 7) (Ayuntamiento de Madrid, 2016a).

Figura 7: Zonas verdes de El Retiro

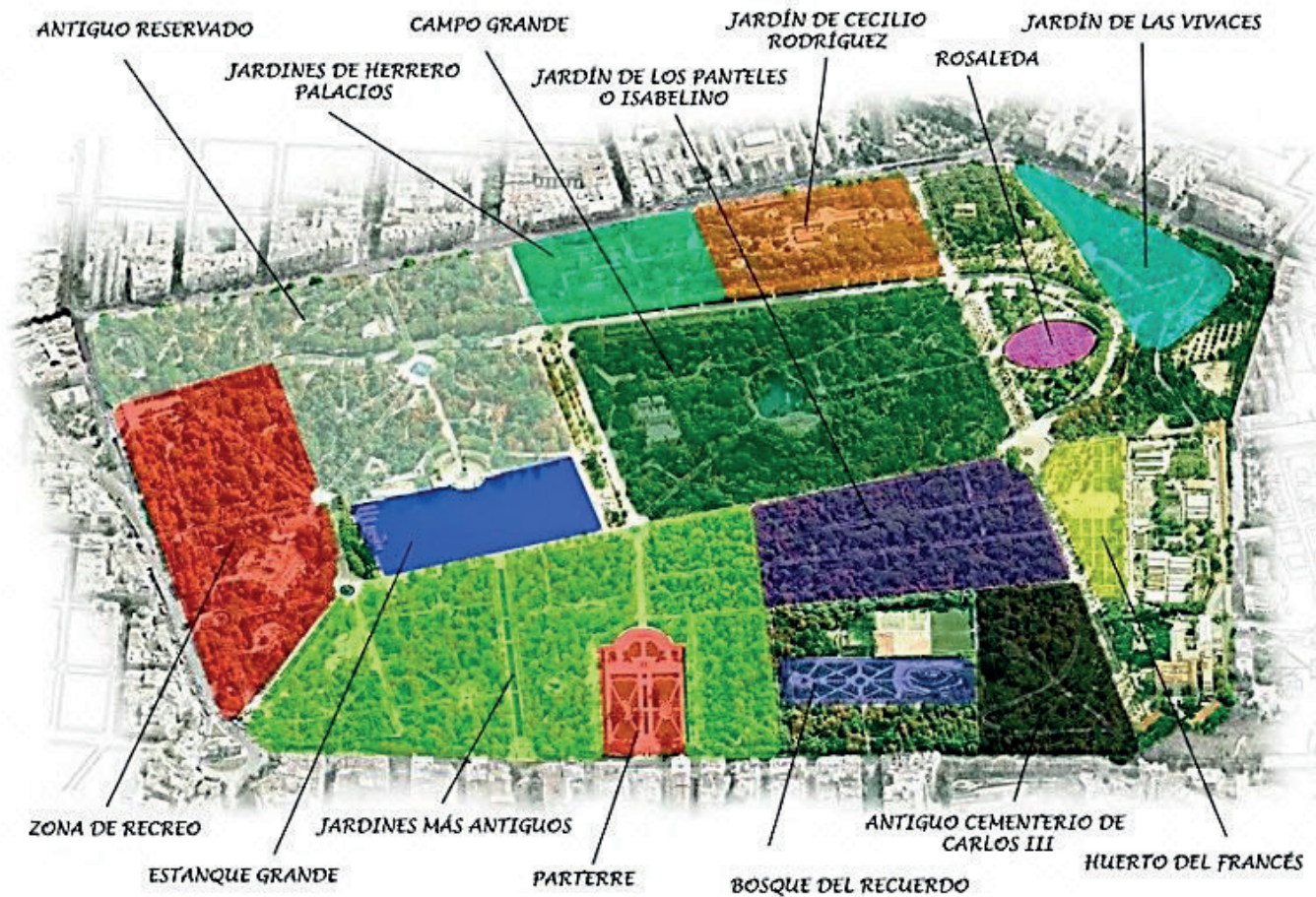

Fuente: Elaboración propia a partir de información del Ayuntamiento de Madrid. 
Los jardines más antiguos se encuentran en la zona oeste, donde destaca el Parterre, jardín de estilo francés diseñado con Felipe V y posteriormente modificado con Isabel II. Ocupa el lugar del antiguo jardín ochavado existente con Felipe IV y Carlos II.

En el lado oriental, el Antiguo Reservado hace referencia al espacio que se reservó Fernando VII, tras los desastres de la Guerra de Independencia, realizando en el mismo los denominados "caprichos", tan de moda en los jardines románticos de la época. Aunque reformados, algunos han pervivido hasta la actualidad, como la Casita del Pescador, la Montaña Artificial, la Casa de Vacas y la Casa del Contrabandista. Las dos últimas están muy modificadas y hoy en día convertidas respectivamente en un centro cultural y en Florida Retiro, un espacio de restauración y espectáculos. Otros caprichos fueron demolidos enteramente, como las Casas del Rico y del Pobre y la Casa Rústica o Persa.

También en el siglo XIX, con Isabel II se crea en 1841 el Jardín de los Planteles o Isabelino, de trazado geométrico con numerosos setos y árboles de sombra. El Campo Grande, lugar para la caza menor hasta mediados del siglo XIX, fue ajardinado en esta misma época, aunque su transformación en jardín paisajista, que ha perdurado hasta la actualidad, se realizó en 1878, cuando ya era propiedad municipal. Posteriormente, en este espacio se levantaron el Palacio de Velázquez (1883) y el Palacio de Cristal (1887).

En 1905 se inauguró la "Zona de Recreos", con paseos arbolados, kioscos de bebidas y de música, y un teatro hoy desaparecido. Otras incorporaciones realizadas en el siglo XX son: la Rosaleda (1915), los Jardines de Cecilio Rodríguez y de Herrero Palacios (década de los 40) y el Jardín de Vivaces (década de los 60). El bosque del Recuerdo, inaugurado en marzo de 2005 y dedicado a las víctimas del atentado del 11 de marzo de 2004, es el último espacio verde creado en El Retiro.

\subsection{El agua en El Retiro: fuentes, estanques y rías}

El agua, muy presente en El Retiro, en su origen sirvió para el disfrute de la monarquía, mediante la navegación en falúas o góndolas por los canales y estanques. De ellos, el Estanque de las Campanillas y el Estanque Grande, con su diseño actual, son los únicos elementos que se conservan desde el siglo XVII. En el segundo de ellos se realizaron representaciones teatrales y naumaquias hasta finales del siglo XIX (Mariblanca, 1991 y 2008)

\section{Figura 8: Una de las dos fuentes simétricas denominadas de la Alcachofa del Parterre (1712) Al fondo el Ahuehuete}

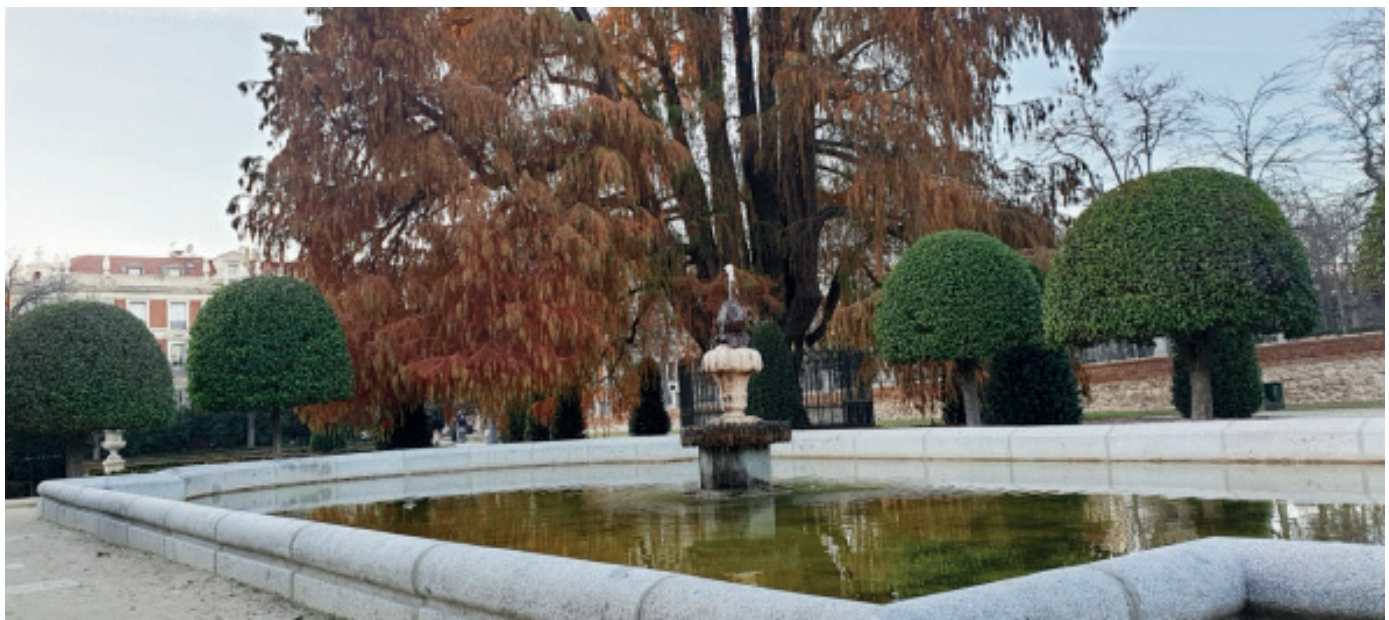

Fuente: Elaboración propia.

Las fuentes monumentales (Tabla 2 y Fig. 8), en su mayoría de estilo barroco, representan pasajes mitológicos, como la fuente de La Alcachofa o de los Tritones (1781-1782). Destaca por su originalidad y exotismo la fuente egipcia (1819-1850), conocida por los madrileños como "la tripona". 
Las rías, acompañadas de puentes, pasarelas y vegetación, son itinerarios sofisticados que han servido tanto para su navegación como pistas de patinaje, durante los rigurosos inviernos de hace pocas décadas.

Tabla 2: Fuentes, Estanques y Rías de El Retiro.

\begin{tabular}{|c|c|c|c|c|c|}
\hline Fuentes & Fecha & Estanques & Fecha & Rias & Fecha \\
\hline Fuente de Cupido de La Rosaleda & 1700 & Estanque de las Campanillas & 1632 & $\begin{array}{l}\text { Ria Norte y estanque de la } \\
\text { Montaña Artificial del Retiro }\end{array}$ & 1817 \\
\hline Fuente del Fauno de La Rosaleda & 1700 & Estanque grande del Retiro & 1634 & Ria del paseo de Colombia & \pm 1900 \\
\hline Fuentes de la Alcachofa del Parterre & 1712 & $\begin{array}{l}\text { Estanque del Palacio de Cristal } \\
\text { Estanques gemelos de la antigua }\end{array}$ & 1887 & $\begin{array}{l}\text { Ria del paseo de Venezuela } \\
\text { Ria Sur y cascada de la }\end{array}$ & \pm 1900 \\
\hline Fuente con escudo de Madrid & 1750 & Casa de Fieras & 1918 & Chopera & \pm 1900 \\
\hline Fuente del pequeño tritón & 1750 & $\begin{array}{l}\text { Estanque pequeño de los jardines de } \\
\text { Cecilio Rodríguez } \\
\text { Estanques en cascada de los jardines }\end{array}$ & 1925 & & \\
\hline Fuente de la Alcachofa & 1781 & de Cecilio Rodríguez & 1925 & & \\
\hline Fuente Egipcia & 1819 & Estanque óvalo del Retiro & 1940 & & \\
\hline Fuente de Isabel II o de los galápagos & 1831 & Estanque Central de La Rosaleda & 1941 & & \\
\hline Fuente de la Concha del Parterre & 1841 & Estanque del jardin de Vivaces & 1965 & & \\
\hline Fuente de los Delfines del Parterre & 1841 & $\begin{array}{l}\text { Estanque del Bosque de los Ausentes } \\
\text { Estanque e isla ovalada del Parque }\end{array}$ & 2005 & & \\
\hline Fuente de las Cuatro náyades o de las Sirenas & 1900 & $\begin{array}{l}\text { del Retiro } \\
\text { Estanque rústico y puente de los }\end{array}$ & \pm 1870 & & \\
\hline Fuente en la plaza del Mármol & 1941 & jardines de Cecilio Rodriguez & \pm 1929 & & \\
\hline Fuente de la Gaviota & 1962 & & & & \\
\hline Fuente de la Sardana & 1964 & & & & \\
\hline Fuente de Sevilla & 1995 & & & & \\
\hline Fuente nueva de los Delfines del Parterre & 2001 & & & & \\
\hline Fuente de la Gruta & \pm 1825 & & & & \\
\hline Fontines del jardin de los Planteles del Retiro & \pm 1865 & & & & \\
\hline
\end{tabular}

Fuente: Elaboración propia a partir de datos del Ayuntamiento de Madrid, 2019b.

\subsection{Otros bienes patrimoniales arquitectónicos y artísticos}

En la vertiente arquitectónica cabe destacar el Palacio de Velázquez y el Palacio de Cristal, ambos sedes de exposiciones temporales del Museo Nacional Centro de Arte Reina Sofía (4. y 5.3.1.). Entre las modestas edificaciones restantes (tabla 3) destaca por su antigüedad la Ermita de San Pelayo y San Isidoro, situada originalmente extramuros de la ciudad de Ávila. Desde 1896 pasó a formar parte del patrimonio de El Retiro (Ayuntamiento de Madrid, 2019c).

Tabla 3: Bienes arquitectónicos de El Retiro.

\begin{tabular}{|lc|}
\hline \multicolumn{2}{|c|}{ Edificación singular } \\
\hline Ruinas de la ermita de San Pelayo y San Isidoro & 1050 \\
Casa del Pescador del Retiro & 1817 \\
Palacio de Velázquez & 1883 \\
Palacio de Cristal & 1887 \\
Embarcadero del Estanque de El Retiro & 1917 \\
Noria de la Fábrica de Porcelana & 2000 \\
\hline
\end{tabular}

Fuente: Fuente: Elaboración propia a partir de datos del Ayuntamiento de Madrid, 2019b.

La Noria de la Fábrica de Porcelana es el único remanente que queda de dicha instalación. Creada por Carlos III, su desaparición no fue debida a las tropas francesas, como ocurrió con otros bienes inmersos en la fortificación en la que convirtieron El Retiro. Las tropas inglesas, entonces aliadas de España, consiguieron reducir a las anteriores y oportunamente arrasaron lo que quedaba de la fábrica de cerámica, eliminando así un competidor en dicha manufactura (Aparisi, 2011a).

El Retiro presenta una notable colección de esculturas (Tabla 4), en su mayoría conmemorativas de personajes de los ámbitos histórico, literario, científico, artístico y mitológico, lo que le confiere un valor artístico y educativo. Su ubicación en lugares destacados del parque contribuye al equilibrio y armonía con el entorno natural. 
Figura 9: Paseo de Argentina, que une la puerta de España con el Estanque Grande, jalonado por esculturas de monarcas españoles, en su origen destinadas al Palacio Real

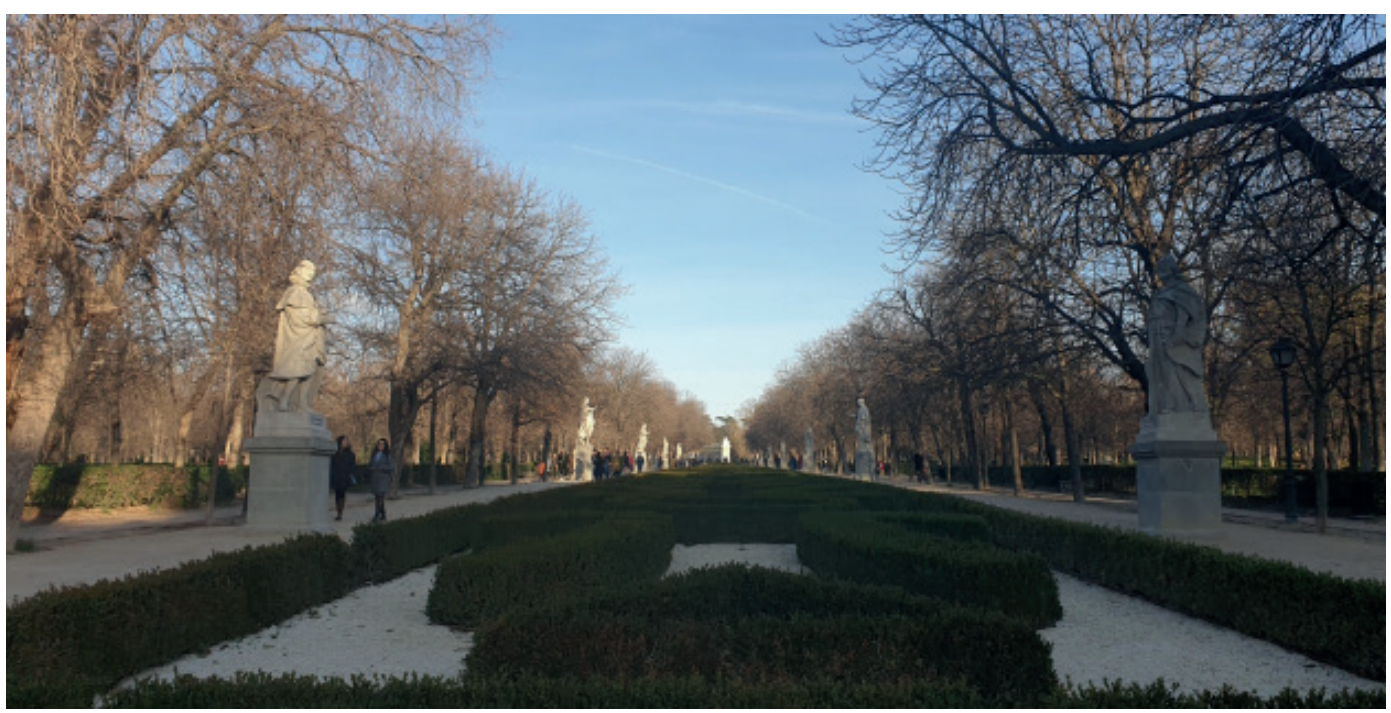

Fuente: Elaboración propia.

Los conjuntos escultóricos focalizan la atracción de los visitantes, en especial el dedicado a Alfonso XII, monumento emblemático de El Retiro, ubicado en el lugar más visible del parque, junto al Estanque Grande (Fig. 10). Diseñado por José Grases Riera y otra veintena de escultores participantes en el proyecto en 1901 (García, 2017), es una estructura de grandes dimensiones con una columnata semicircular, la estatua ecuestre del monarca, que culmina la torre mirador, una escalinata y numerosos elementos escultóricos acompañantes (Peña, 2011).

Figura 10. Estanque Grande con el monumento Alfonso XII al fondo.

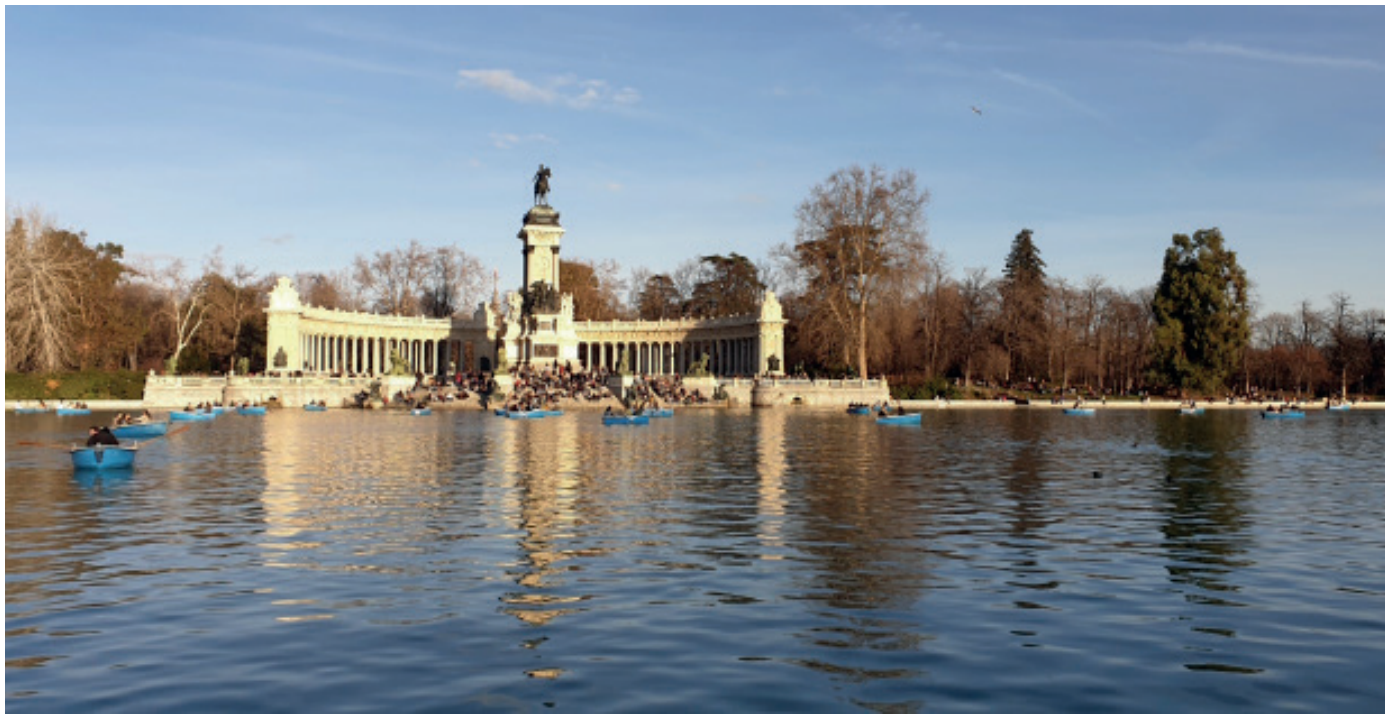

Fuente: Elaboración propia. 
En el ámbito mitológico destaca El Ángel Caído, monumento dedicado a Lucifer realizado en 1887 por Ricardo Bellver Ramón y Francisco Jareño y Alarcón. Fue donada por Alfonso XII al Ayuntamiento de Madrid (Ayuntamiento de Madrid, 2019c).

Tabla 4: Inventario de la colección escultórica de El Retiro.

\begin{tabular}{|c|c|c|c|c|c|c|c|}
\hline $\begin{array}{l}\text { Estatuas } \\
\text { Reyes españoles }\end{array}$ & Fecha & Otras estatuas & Fecha & Grupo Escultórico & Fecha & Esculturas abstractas & Fecha \\
\hline Alonso I El Batallador & 1743 & Diana & 1750 & Hércules y el León de Nemea & 1650 & Dados de Hormigón & 1982 \\
\hline Berenguela & 1743 & Diosa Hera & 1750 & Hércules y la Hidra de Lerna & 1650 & Enrique Tierno Galván & 1986 \\
\hline Carlos I & 1743 & Juan Van-Halen y Sarti & 1846 & Osos sentados de la Casa de Fieras & 1850 & & \\
\hline Carlos II & 1743 & Thalia & 1860 & Alfonso XII & 1901 & & \\
\hline Chintila & 1743 & El Ángel Caido & 1877 & Campoamor & 1912 & & \\
\hline Enrique II & 1743 & Doctor Benavente & 1885 & Ruperto Chapi & 1917 & & \\
\hline Fernando IV & 1743 & General Martinez Campos & 1907 & Santiago Ramón y Cajal & 1923 & & \\
\hline Garcia I Rey de León & 1743 & Chueca & 1909 & Cuba & 1929 & & \\
\hline Gundemaro & 1743 & Benito Pérez Galdós & 1919 & Francisco de Paula Marti Mora & 1961 & & \\
\hline Ramón Berenguer IV & 1743 & Fray Pedro Ponce de León & 1920 & & & & \\
\hline Sancho IV & 1743 & Doctor Cortezo & 1921 & & & & \\
\hline Sancho IV. El Bravo & 1743 & Tolosa Latour & 1925 & & & & \\
\hline \multirow[t]{7}{*}{ Urraca } & 1743 & Ricardo Codorniu & 1926 & & & & \\
\hline & & Miguel Moya & 1927 & & & & \\
\hline & & Mujer sedente & 1943 & & & & \\
\hline & & Jacinto Verdaguer & 1953 & & & & \\
\hline & & $\begin{array}{l}\text { Doctor Ángel Pulido } \\
\text { Fernández }\end{array}$ & 1954 & & & & \\
\hline & & Jacinto Benavente & 1961 & & & & \\
\hline & & Andrés Eloy Blanco & 1975 & & & & \\
\hline
\end{tabular}

Fuente: Elaboración propia a partir de datos del Ayuntamiento de Madrid, 2019b.

El Retiro tiene dieciocho puertas (Tabla 5) que hacen de él un espacio abierto a la ciudadanía. La monumentalidad de doce de ellas, como la Puerta de Felipe IV, construida en 1690 o la Puerta de España, en 1891 (Fig. 11), es otro atractivo del parque, que en su momento contribuyó a la pompa de las comitivas oficiales que accedía al recinto. De la misma manera contribuyó el cerramiento de forja de hierro, que se abordó de forma decidida en 1870. El vistoso cerramiento que presenta El Retiro fue controvertido a lo largo del pasado siglo, con partidarios de su desaparición, al estilo de los grandes parques de otras ciudades europeas. Por otro lado, los que manifestaban su necesaria protección frente al vandalismo, habida cuenta que se trata de un jardín histórico con abundante patrimonio artístico. En el año 2000 queda cerrado a la circulación rodada y, tras una encuesta del ayuntamiento a vecinos y usuarios, en 2001 la Concejalía de Medio Ambiente procede al cierre del parque en horario nocturno (Aguinaga, 2011). 


\section{Figura 11: Puerta de España (1891)}

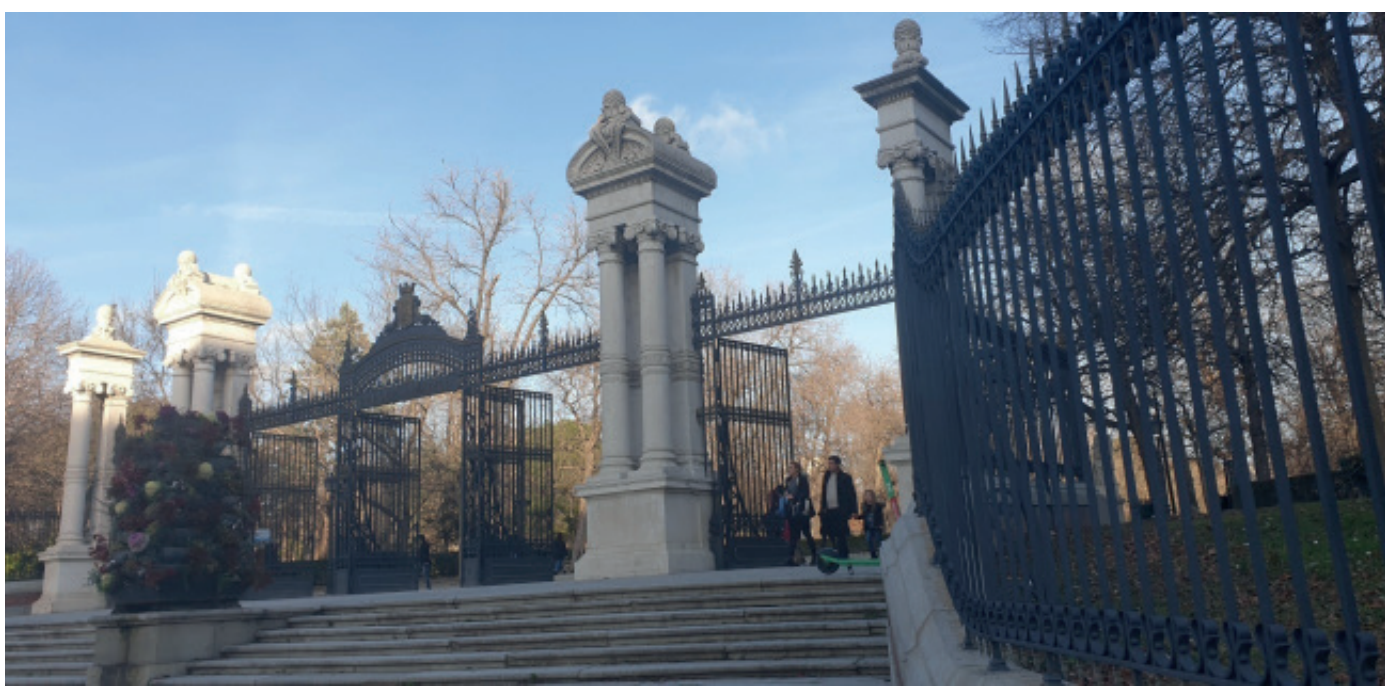

Fuente: Elaboración propia.

Tabla 5: Inventario de puertas, elementos conmemorativos y de ornamentación de El Retiro

\begin{tabular}{|c|c|c|c|c|c|}
\hline Puerta & Fecha & $\begin{array}{l}\text { Elemento conmemorativo, } \\
\text { Lápida }\end{array}$ & Fecha & Elemento de ornamentación & Fecha \\
\hline Puerta de Felipe IV & 1690 & Virgen de los Reyes & 1920 & Jarrones Franceses del Parterre & 1712 \\
\hline Puerta de la Independencia & 1817 & Mariano de Cavia & 1921 & Pedestal del paseo de los Reyes & 1842 \\
\hline Puerta del Olivar de Atocha (J. de C. R.) & 1823 & Luis de Góngora & 1927 & Jarrones de la Rosaleda del Retiro & 1915 \\
\hline Puerta de España & 1891 & Hipólito Yrigoyen & 1928 & Columna-pedestal. J. de C. R. & $=1929$ \\
\hline Puerta de Murillo & 1893 & Julio Romero de Torres & 1932 & Dos columnas. J. de C. R. & \pm 1929 \\
\hline Puerta de Madrid & 1900 & General Francisco Morazán & 1973 & Ocho columnas. J. de C. R. & \pm 1929 \\
\hline Puerta sur de los Jardines de C. R. & 1929 & Mariscal Francisco Solano López & 1976 & Homenaje a la Mar & 1930 \\
\hline Puerta de la América Española & 1932 & Justo Arosemena & 1978 & Pedestal del paseo Duque de Fernán Núñez & \pm 1950 \\
\hline Puerta de Hernani & 1943 & Laurel y Madroño & 1983 & Cruceiro de la plaza de Galicia & 1980 \\
\hline Puerta de O'Donnell & 1945 & Juantxu Rodriguez & \pm 1990 & Jarrones Franceses nuevos del Parterre & 2001 \\
\hline Puerta de la Reina Mercedes & 1950 & & & & \\
\hline Puerta de Sainz de Baranda & 1950 & & & & \\
\hline Puerta de Dante & 1968 & & & & \\
\hline Puerta de Granada & 2000 & & & & \\
\hline Puerta de Herrero Palacios & 2000 & & & & \\
\hline Puerta del Ángel Caido & 2000 & & & & \\
\hline Puerta del Doce de Octubre & 2000 & & & & \\
\hline Puerta del Niño Jesús & 2000 & & & & \\
\hline
\end{tabular}

Fuente: Elaboración propia a partir de datos del Ayuntamiento de Madrid, 2019b.

\section{Principales manifestaciones culturales}

El Retiro ha sido desde sus origenes lugar de representación de numerosos eventos culturales o de ocio. Si nos remontamos al pasado, podemos mencionar los vuelos en globo aerostático ${ }^{14}$ y las naumaquias realizadas en el Estanque Grande. ${ }^{15}$

Mayor huella dejaron la Exposición de Minería y Bellas Artes (1883) y la Exposición de Filipinas (1887), para las que se construyeron el Palacio de Velazquez y el Palacio de Cristal (Fig. 12 y 13), ambos 
debidos al arquitecto Ricardo Velázquez, a quien el primero debe su nombre. El Palacio de Cristal es un invernadero de grandes dimensiones y mayor belleza, que albergó plantas exóticas durante la mencionada exposición. Como ya se ha mencionado, en la actualidad se utilizan como salas de exposiciones temporales del Museo Nacional Centro de Arte Reina Sofía.

\section{Figura 12: El Palacio de Cristal.}

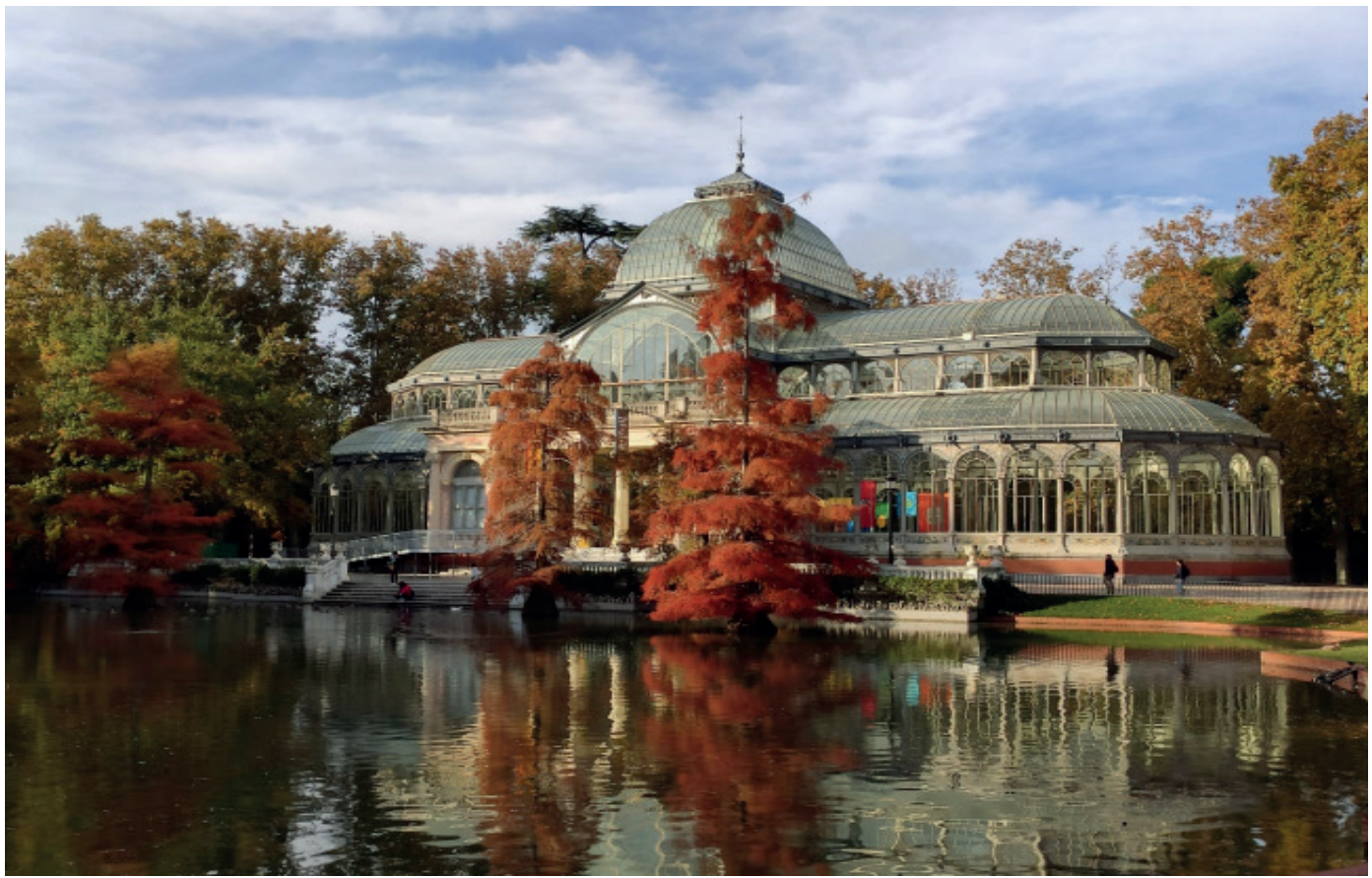

Fuente: Elaboración propia.

Figura 13. Palacio de Velazquez

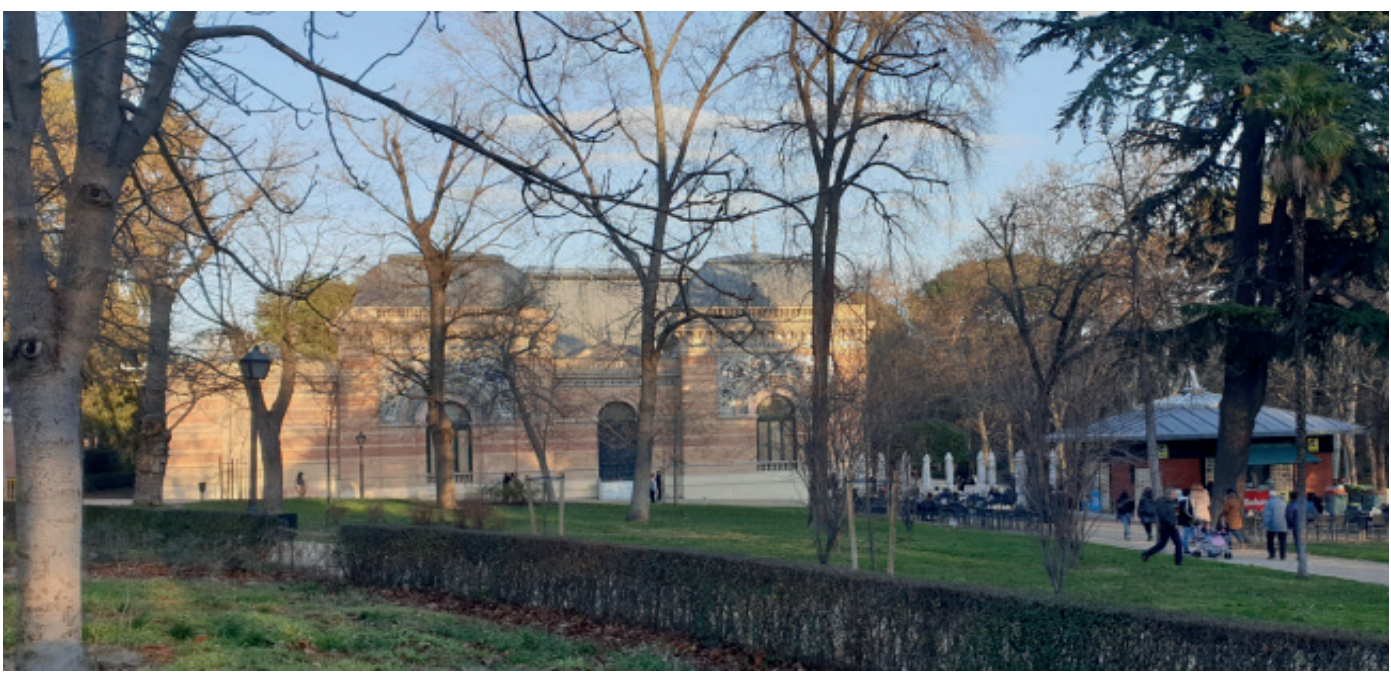

Fuente: Elaboración propia. 
Sin duda, la Casa de Fieras ${ }^{16}$ ha sido el mayor incentivo para el ocio y la visita del Retiro. En mayor o menor medida la fauna exótica siempre ha estado presente en El Retiro, por ser Real Sitio y también ser gusto de la realeza la pertenencia de especies exóticas. En 1634, con Felipe IV, se edificó "La Leonera", cercana a la actual Plaza de la Independencia, (Fig. 4) un recinto ovalado con un foso y jaulas para las fieras que podían ser vistas por la realeza desde una barandilla superior (Aparisi, 2011a). No obstante, la primera colección con mayor importancia, fue un proyecto científico de Carlos III, inaugurado en 1774 como una instalación complementaria al Gabinete de Ciencias Naturales y situada junto al Real Jardín Botánico. Posteriormente Fernando VII ordenó su traslado al edificio de dos plantas conocido como "La Leonera"17, con las jaulas en la planta baja y estancias en la superior (Simón, 1991).

\section{Figura 14: Antigua Casa de Fieras. El edificio "La Leonera" ha sido transformado en la biblioteca municipal Eugenio de Trías.}

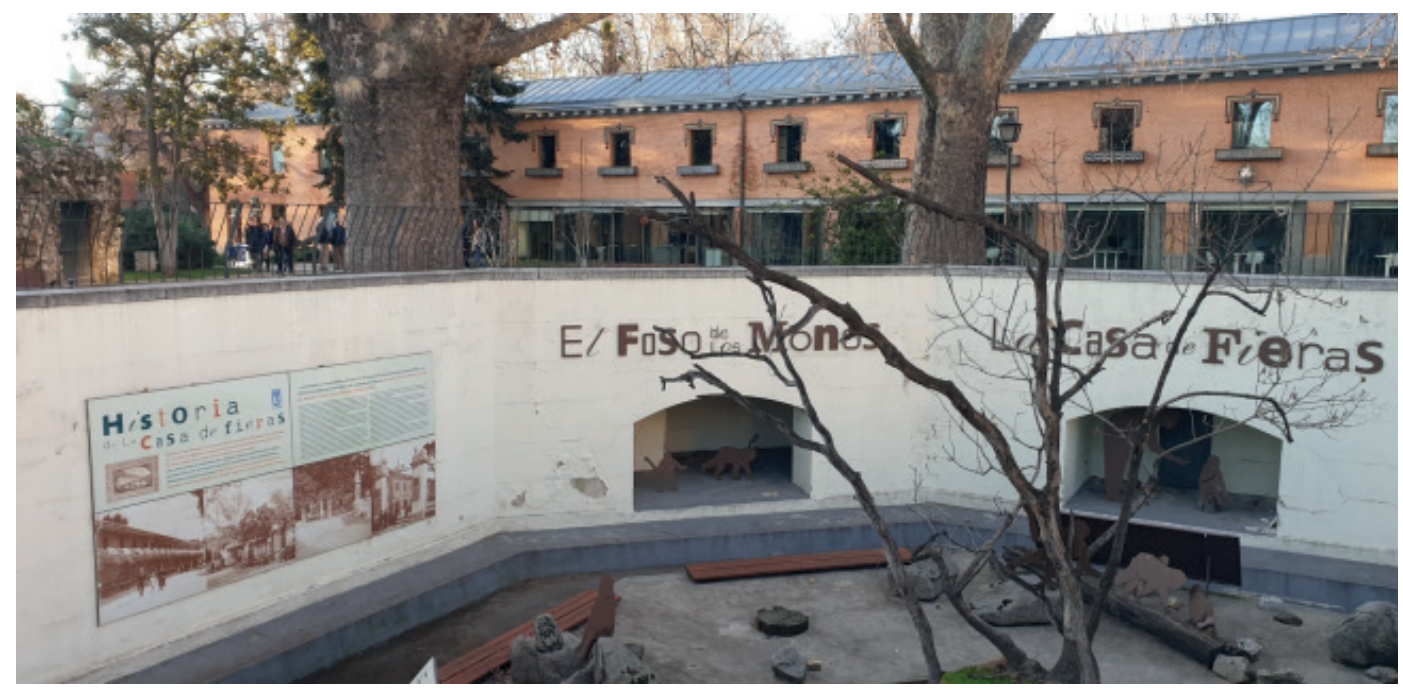

Fuente: Elaboración propia.

En los orígenes de El Retiro la música sirvió para el disfrute de la Corte. Hoy en día el parque es muy frecuentado por artistas callejeros, desde los más clásicos hasta los más alternativos; también por conciertos de la Banda Sinfónica Municipal en el templete de música cercano al Estanque Grande, todos los domingos cuando la meteorología lo permite.

El teatro ha utilizado diferentes espacios a lo largo del tiempo. Primero en las distintas plazas del palacio y en el Coliseo, ya desaparecidos (ver 2.), sin olvidar las naumaquias en el gran estanque. Hoy en día las representaciones teatrales tienen lugar en el Centro Cultural Casa de Vacas y en Florida Retiro; también llegan a los más pequeños con el teatro de títeres al aire libre, que ofrece una amplia programación todos los sábados y domingos a lo largo del año, e incluso un festival internacional anual en los meses de julio y agosto. Se trata de una experiencia de gran tradición y única en Europa (Ayuntamiento de Madrid, 2019d).

La Feria del Libro, ubicada en el paseo de Fernán Núñez, es el evento más conocido y visitado del parque, Desde 1967 reúne durante el mes de junio a libreros, editores, distribuidores, escritores y lectores. Su repercusión es cada vez más grande. Se estima que en 2019 hubo 2,4 millones de visitantes, la gran mayoría de la Comunidad de Madrid (82\%), de otras comunidades autónomas (17\%) y un 1\% procedentes del extranjero (Feria del Libro, 2020).

El Retiro también es lugar de encuentro de diferentes colectivos y asociaciones. Cabe mencionar la asociación amigos de El Retiro "La Cabaña", de carácter vecinal creada en 1981, que tiene su sede en el recinto del parque, donde los asociados practican juegos de mesa y de exterior en un entorno saludable. La Asociación Amigos de los Jardines de El Buen Retiro, desde 2018 viene realizando actividades de divulgación del patrimonio del parque mediante visitas guiadas y conferencias. Por otro parte, el círculo 
del Retiro de Tai Chi Chuan mantiene la práctica del mismo y realiza reuniones anuales desde 2003. También es destacable el activismo reivindicativo con el nombre "puerto seguro", llevado a cabo por Amnistía Internacional en el Estanque Grande (agosto de 2019), en defensa de los migrantes rescatados a la deriva en el mar.

El Aula de ecología La Cabaña del Retiro, gestionada por la Junta Municipal de Distrito de El Retiro, y el Centro de Educación Ambiental de El Retiro realizan actividades para público infantil, juvenil y adulto (itinerarios guiados, talleres, huerto ecológico y arboreto, conferencias, etc.) dirigidas a la población local, así como las actividades deportivas del centro deportivo La Chopera.

\section{Gestión, mantenimiento y uso de El Retiro.}

Se puede afirmar que, gracias a la gestión realizada a lo largo de los siglos, El Retiro presenta un estado de conservación aceptable, si bien son necesarias acciones encaminadas a la mejora de su mantenimiento y solución de problemas existentes. La gestión y mantenimiento del parque presenta la complejidad inherente a su reparto y dispersión entre diferentes organismos de la administración y empresas privadas, lo que en ocasiones dificulta el seguimiento de acciones prioritarias claras, produciéndose ocasionales ausencias de responsabilidades.

\subsection{Los Jardines}

La gran variedad de especies ha provocado una necesaria transformación del suelo autóctono, ya que muchas de ellas son foráneas y necesitan un PH calcáreo específico, que no es precisamente una característica del suelo de Madrid, cuya pobreza en arcilla y nutrientes obliga en muchos casos a su abonado mediante fertilizantes de liberación lenta, con nitrógeno, potasa y fósforo.

También merece especial atención el impacto del arbolado sobre el patrimonio monumental, dado que el desarrollo radicular de aquél llega a afectar a este, haciendo necesaria la creación de pantallas enterradas y un estudio específico de la obra necesaria en cada caso. En suma, puede concluirse que el cuidado de esta masa arbórea en el entorno monumental, no es sencillo.

Tratando de afrontar los diversos y numerosos problemas de mantenimiento, en 2016 se creó el Plan Director del arbolado de los Jardines del Buen Retiro, en parte inducido por las caídas de algunos árboles, sin razón aparente ni enfermedades registradas. Con una vigencia de 50 años, estipula su revisión y actualización cada cinco. Este plan pretende diagnosticar las actuaciones necesarias para lograr un arbolado seguro y de calidad (Ayuntamiento de Madrid, 2016a). Para ello se realiza la gestión por zonas del mismo origen, uso y tipología de arbolado y jardinería, dando prioridad al estudio de riesgos y a su revisión periódica. Algunas de las acciones que se llevan a cabo pretenden hacer frente a diversas amenazas como son: fuertes vientos ocasionales, exceso de nitrógeno en algunas zonas, especies invasoras de avifauna, enfermedades fúngicas u otras, como "la socarrina", referible a las quemaduras de los castaños por el sol.

Sin embargo, la principal amenaza es la elevada afluencia de visitantes y usuarios a los Jardines. "Todos los ciudadanos tienen derecho al uso y disfrute de los Jardines del Buen Retiro, (...) pero también el deber y obligación de respetar cualquier elemento del parque, incluido su arbolado" (Ayuntamiento de Madrid, 2016a).

\subsection{Materiales de información turística y de actividades}

El Centro de Información y Educación Ambiental el Huerto del Retiro, gestionado por el Ayuntamiento de Madrid, es en la actualidad el centro con la información más completa del parque, y a su vez también gestiona el Punto de Información del Bosque del Recuerdo, localizado en una antigua cabaña próxima a la calle de Alfonso XII. (Ayuntamiento de Madrid, 2019e). Paralelamente, la Cabaña de El Retiro y el Centro Cultural Casa de Vacas también proporcionan información parcial.

El parque es visitable mediante rutas guiadas. Las rutas oficiales son ofrecidas por el Centro de Información y Educación Ambiental el Huerto del Retiro y por el aula de ecología: La Cabaña del Retiro. Diversas empresas privadas desarrollan rutas a pie o bien en Segway y bicicletas. Por otro lado, las asociaciones sin ánimo de lucro: Asociación de Amigos de los Jardines del Buen Retiro y Asociación Rutas Alter Matrice, así como el Plan Director del Arbolado de los Jardines del Retiro, organizan conferencias y diversas rutas por el parque.

No hay un portal web que englobe e informe de todas las actividades que tienen lugar en el parque. Dicha información aparece dispersa en el Centro de Información y Educación Ambiental el Huerto 
del Retiro y en La Cabaña del Retiro. Esta última se publicita a través de sus redes sociales y con el sistema de mensajería a los socios registrados, tras haber realizado una actividad. Ambos centros no aparecen coordinados entre sí.

Las empresas privadas publicitan sus actividades en sus páginas web, en tanto que el ayuntamiento ha desarrollado su propia App para la visita (Ayuntamiento de Madrid, 2016b), pero sin referencias a las anteriores. Se hace notar la descoordinación en este aspecto, dado que los informadores de los dos recintos oficiales de información ubicados en el parque no advierten de la existencia de la App del Retiro.

Aunque escasa y de tamaño reducido, la cartelería del parque proporciona información de interés sobre los elementos patrimoniales del parque (Fig.15).

\section{Figura 15: El reducido tamaño de la cartelería} del parque puede no incentivar su lectura.

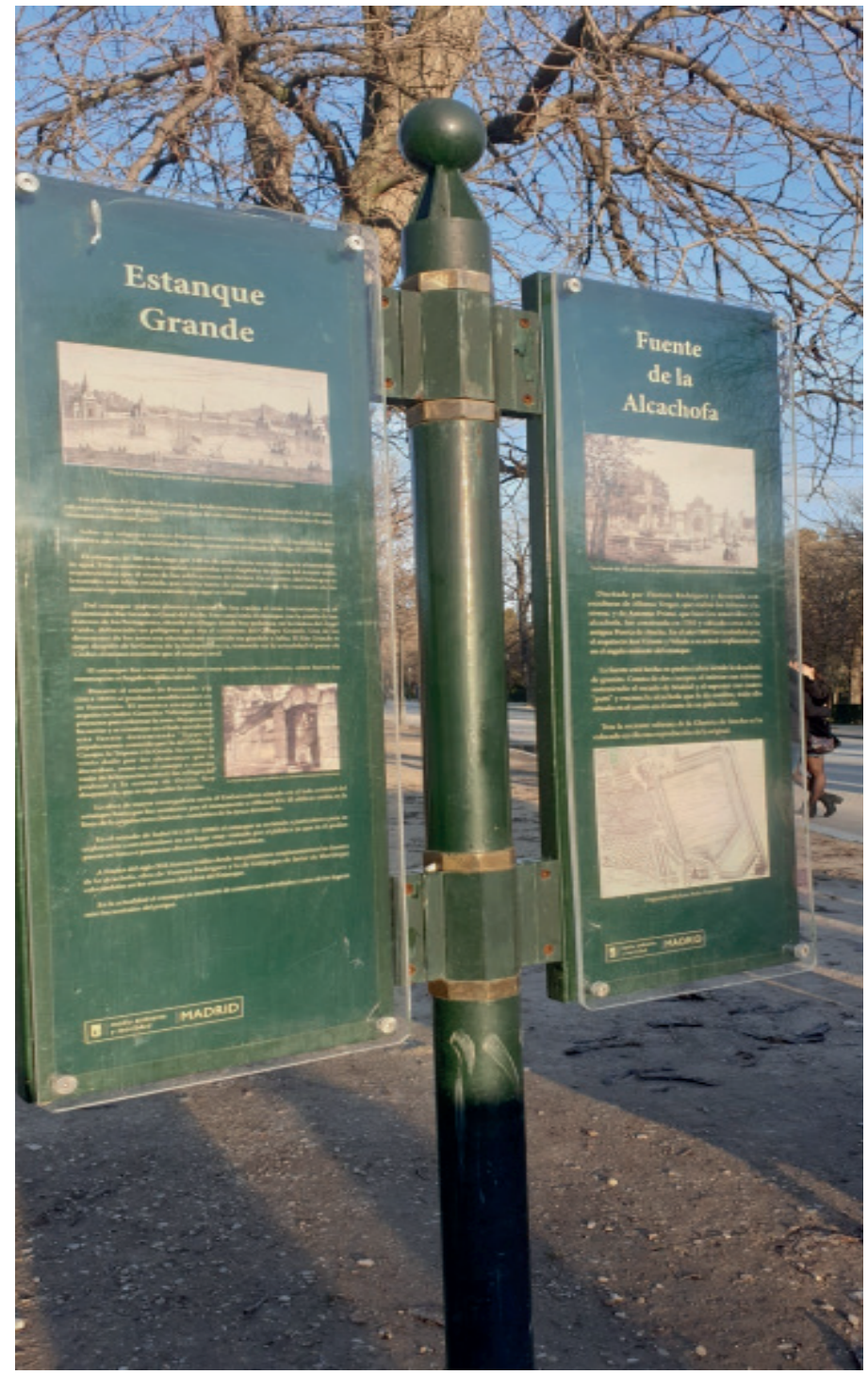

Fuente: Elaboración propia. 


\subsection{Los visitantes}

El Retiro recibe más de 15 millones de visitas cada año, cerca de 2,5 millones durante el mes dedicado a la Feria del Libro (Ayuntamiento de Madrid, 2016a). Es un lugar muy transitado, no solo por los madrileños, también por visitantes foráneos, al ser colindante con el eje del Paseo del Prado y sus distintos museos.

Para aproximarnos al uso que madrileños y turistas hacen de este espacio singular, se ha realizado una encuesta ${ }^{18}$ a 350 individuos, en horarios y días diferentes. En el perfil de los encuestados predomina la población femenina, un 60,3\%, así como los visitantes jóvenes (el 44\% de 20 a 35 años, el 31,7\% de 35 a 55 y el 14,6\% de 55 a 65). En relación con su procedencia (Fig. 16) los visitantes de la capital y de la Comunidad madrileña solo superan levemente el $50 \%$ del total, frente al 46,3\% de foráneos. Un buen indicador del importante uso turístico del parque.

\section{Figura 16: Lugar de origen, frecuencia y forma de visita}

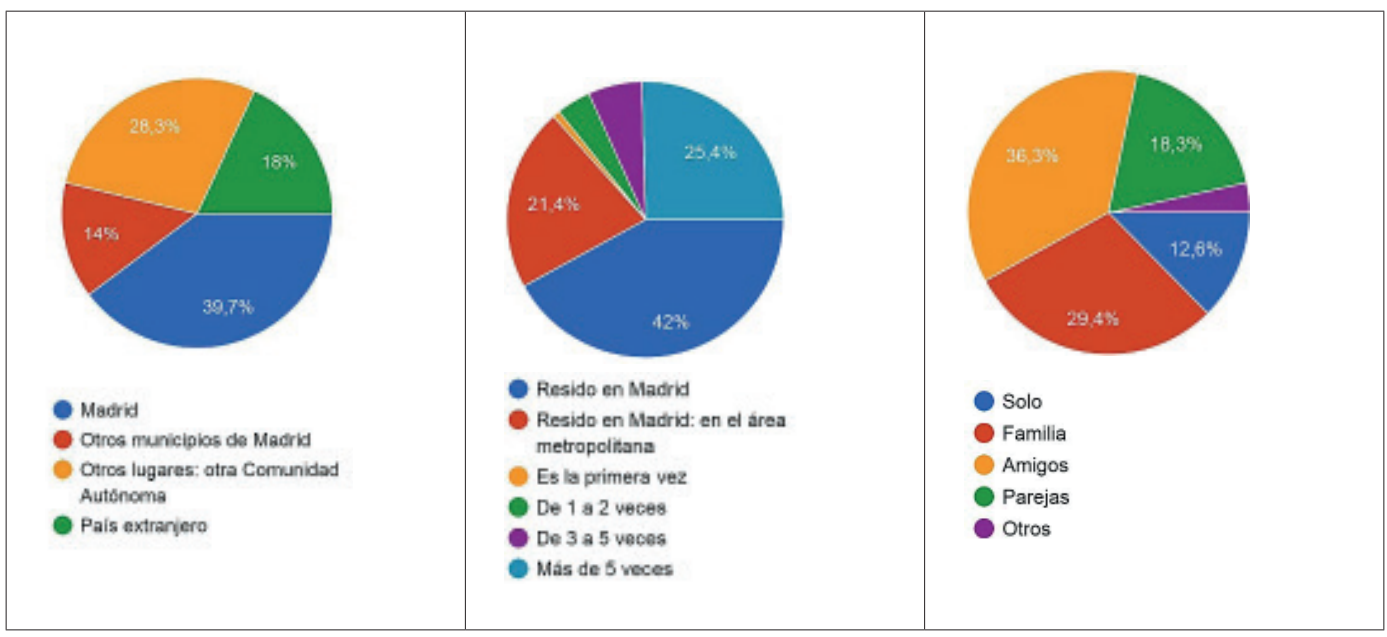

Fuente: Encuesta realizada, elaboración propia.

Entre los visitantes de origen extranjero predominan los franceses, italianos, argentinos y portugueses, seguidos de colombianos, estadounidenses, alemanes, británicos, chinos y japoneses, además de rusos, ucranianos, turcos y búlgaros. En la distribución temporal de las visitas el 76,6\% se realizan el fin de semana y el 23,4 \% entre semana.

El Retiro es objeto de visitas reiteradas, incluso más de 5 en el $25,4 \%$ de los casos, e independientemente de su frecuencia, tienden a ser compartidas en grupos de amigos (36,3\%), en familias (29,4\%), o en parejas $(18,3 \%)$. Años atrás el imaginario social consideraba está últimas como las más asiduas del parque.

\subsubsection{Preferencias y nivel de información.}

Según las mismas encuestas, se evidencia un amplio predominio en la percepción del parque como lugar de paseo, aderezado con visitas a exposiciones, a las barcas del estanque, o algunos de los recursos naturales y culturales, entre los que destacan: la Rosaleda, el Bosque del Recuerdo, los Jardines de Cecilio Rodríguez, árboles singulares y el Parterre en cuanto a las zonas verdes. En los recursos monumentales destacan el Palacio de Cristal, el Estanque Grande y su embarcadero, junto con el monumento a Alfonso XII, fuentes y esculturas. Por el contrario, el Palacio de Velázquez y el Antiguo Reservado de Fernando VII son poco conocidos (Fig. 17).

Entre todos ellos, el Palacio de Cristal destaca como meta principal en la visita al Retiro. La gran afluencia al palacio resulta principalmente de la trasmisión oral de su belleza; también de su promoción en páginas web, oficinas de turismo e incluso estaciones de metro de la ciudad. Su estructura metálica, enteramente acristala y diáfana en su interior, permite admirar el arbolado y estanque circundantes. 
Como todos los lugares singulares, invadidos especialmente en fechas vacacionales, este no es una excepción. El mediano tamaño del edificio y la entrada gratuita al mismo hacen que, en los días festivos, los visitantes del interior se vean impelidos hacia la salida por otros recién llegados.

Por otra parte, las encuestas a los visitantes y sus comentarios espontáneos muestran un desconocimiento bastante general sobre su origen, historia y función actual. Por ser ésta, al igual que el Palacio de Velázquez, sede de exposiciones temporales del Museo Nacional Centro de Arte Reina Sofía, el interior del gran invernadero suele estar ocupado por obras de arte moderno que suelen sorprender a los visitantes. Resulta así que el Museo Reina Sofía es uno de los 20 museos más visitados del mundo, superando al Prado ${ }^{19}$ de forma sorprendente.

En consecuencia, parece necesario establecer un control en la afluencia a dicho recinto, en especial los días de gran concurrencia; evitando el hacinamiento y propiciando un mayor disfrute de la visita, la cual también podría verse enriquecida con un buen diseño de información gráfica sobre el origen e historia del palacio, bien en el interior del mismo o en sus inmediaciones. La información actual se reduce a un pequeño panel situado cerca del edificio.

Contrariamente, el Palacio de Velázquez, aun siendo también sede de exposiciones temporales del mismo museo, solo participa ínfimamente en el cómputo total de visitantes. Su edificio (Fig.13) no posee el exotismo del Palacio de Cristal, su escalinata de acceso y aspecto regio, parecen disuadir a la mayoría de visitantes, que también se ven asaltados por la duda sobre su gratuidad. Es evidente que la información y promoción de este recinto son insuficientes.

En el conocimiento de los recursos históricos por parte de los visitantes destaca la antigua Casa de Fieras, conocida por un $50 \%$ de los entrevistados, en los que predominan los de edad avanzada. Un $36 \%$, jóvenes en su mayoría, desconoce todos los recursos históricos.

En cuanto a las actividades, la Feria del Libro es conocida por el 90,6\% de los encuestados, dada su alta proyección y publicidad. Las actividades programadas, como los conciertos y teatro de títeres, presentan un público con información previa, también con aquel debido al encuentro casual de los paseantes.

Por otro lado, el 92\%, no ha realizado una visita guiada, aunque el 81,4 \% de los mismos la realizaría, lo que evidencia que las rutas ofertadas en el parque están infrautilizadas, por falta de información al respecto. Muchos de los encuestados desconocen su existencia, o la app del Retiro con dicha información. $\mathrm{Al}$ parecer tampoco los informadores hacen referencia a dicho recurso.

Figura 17: Finalidad de la visita, recursos y actividades más visitadas.

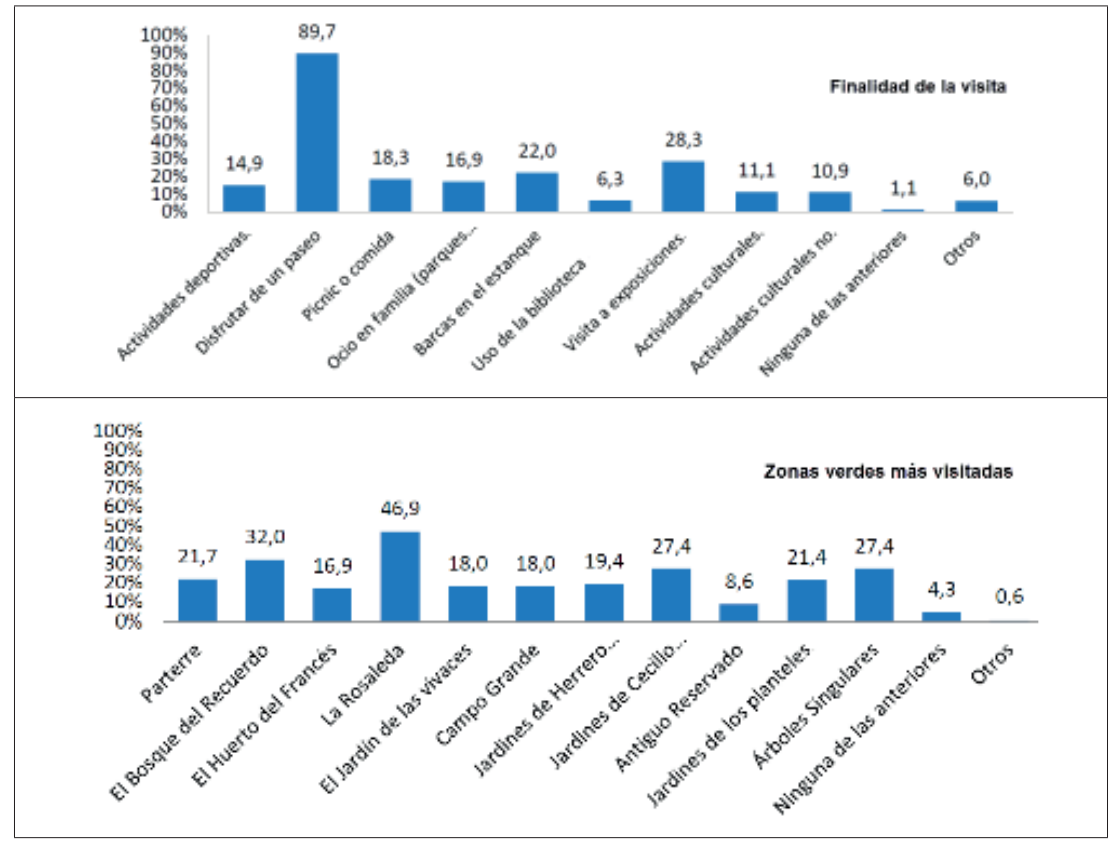


Figura 17: Finalidad de la visita, recursos y actividades más visitadas. (continuación)

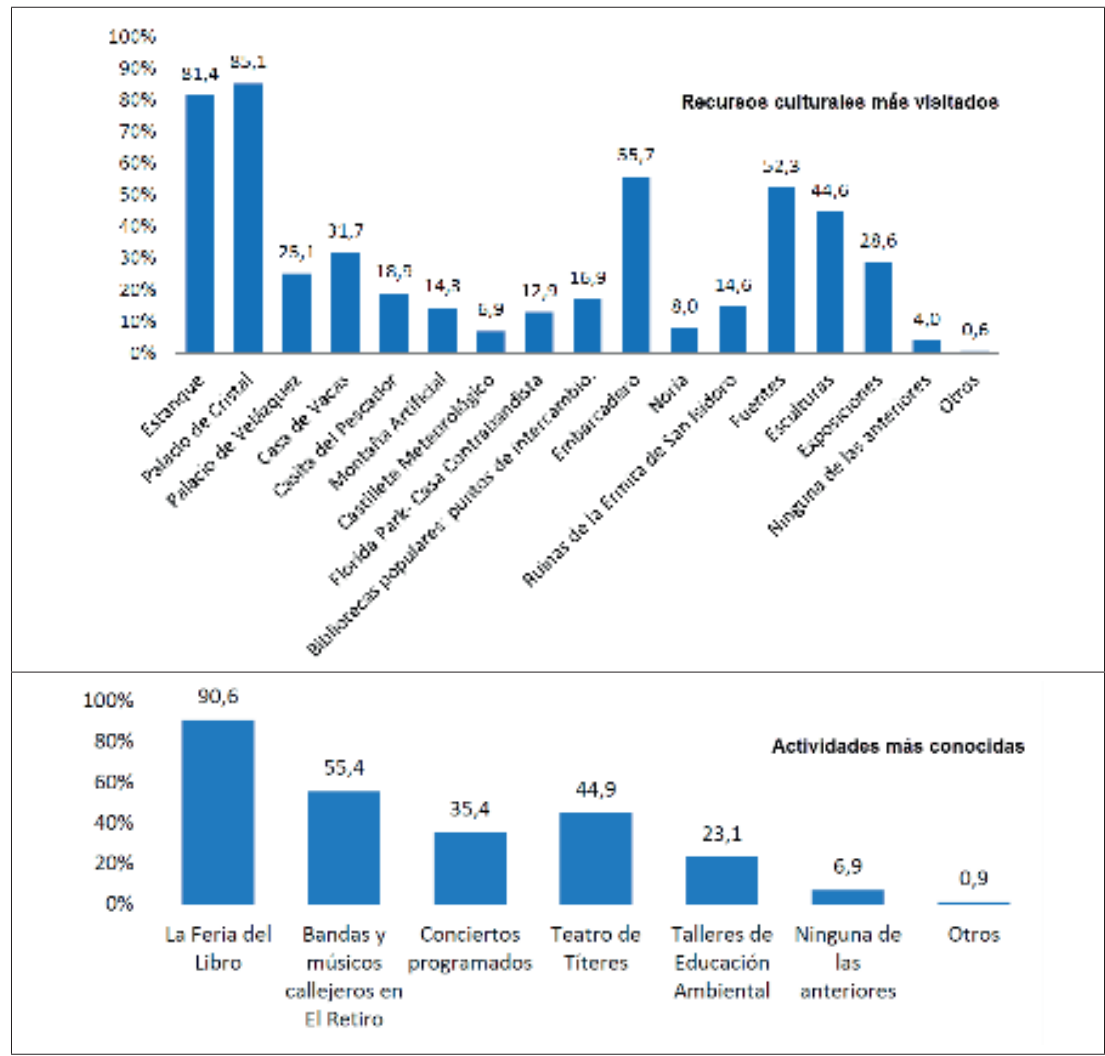

Fuente: Encuesta realizada, elaboración propia.

\subsubsection{Valoración de los componentes del parque, flujos principales y percepción global.}

Los paseos, monumentos y el arbolado alcanzan bastante aceptación. No así los componentes más circunstanciales, como son la información y la señalización (Fig. 18).

\section{Figura 18: La Gestión de El Retiro}

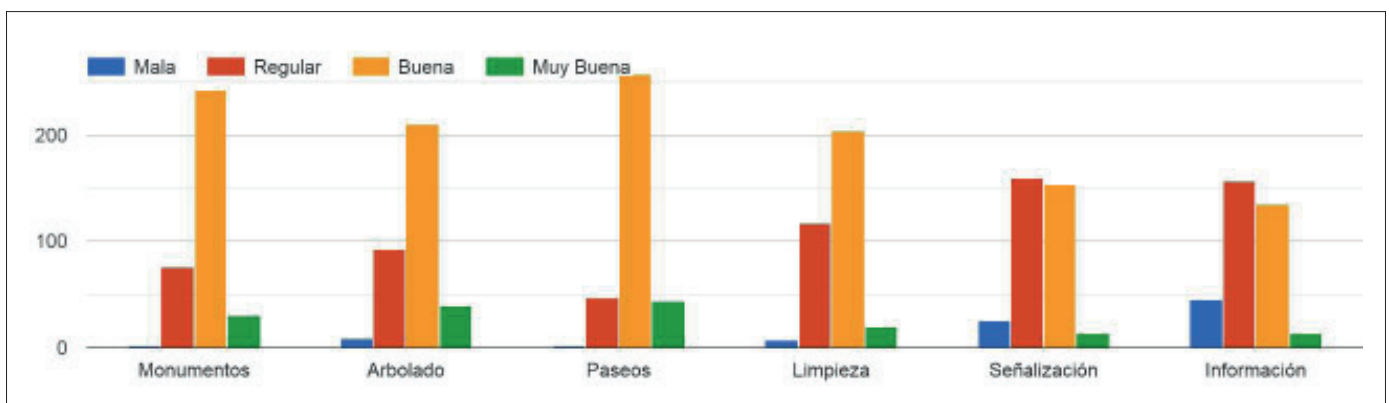

Fuente: Encuesta realizada, elaboración propia.

La Figura 19 muestra las vías del parque más frecuentadas por los visitantes, que vienen a ser aquellas con pavimento y más cómodas de transitar, con una entrada principal en la Puerta de Alcalá (Pza. de la Independencia) y otros tres accesos (Puerta de Felipe IV, Puerta de España y Puerta del 
Ángel Caído) en el lado occidental del parque. El lado oriental es menos frecuentado por el turismo, - exceptuando el periodo correspondiente a la Feria del libro - no así por los locales y el vecindario, donde realizan sus actividades deportivas o recreativas.

\section{Figura 19. Itinerarios más frecuentados por los visitantes.}

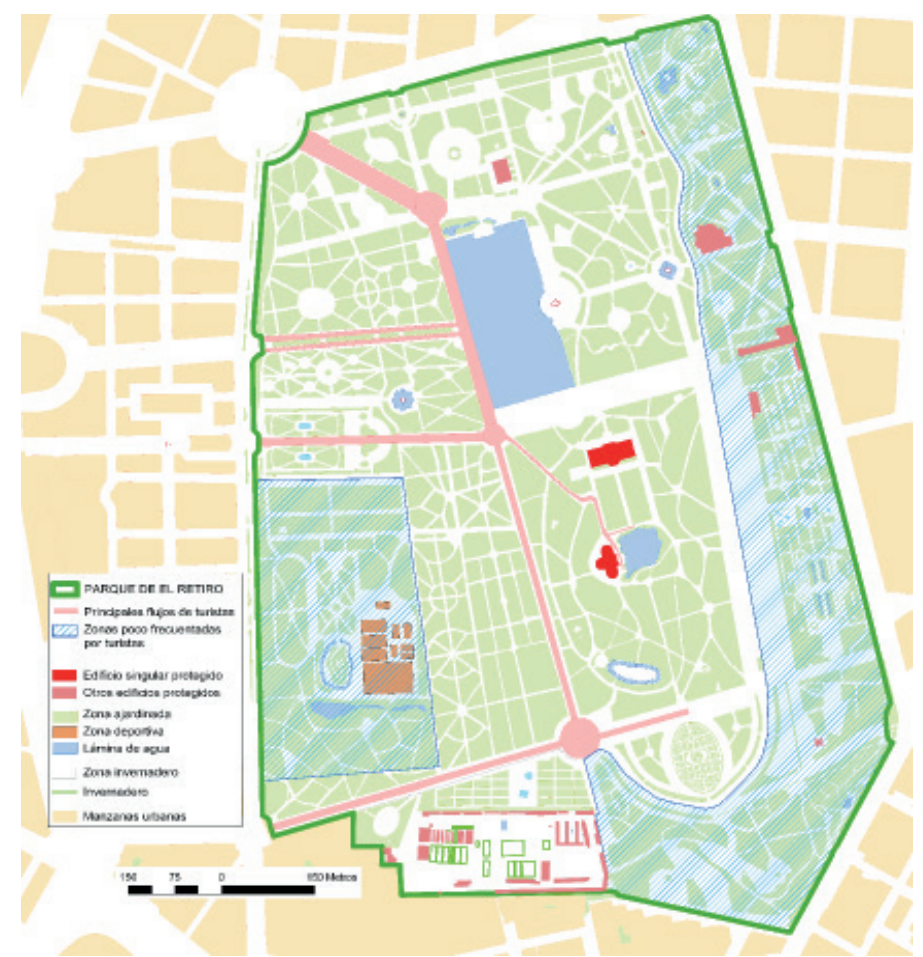

Fuente: Elaboración propia.

Entre los edificios singulares y protegidos, solo el Palacio de Cristal forma parte de estos flujos, en tanto que el Palacio de Velázquez, próximo al anterior, es muy poco visitado, al igual que otros recursos localizados en su mayoría en el sector oriental: Caprichos de Fernando VII, Florida Retiro, la biblioteca Eugenio Trías - ubicada en la antigua Casa de Fieras -, o los jardines de Cecilio Rodríguez.

En la percepción global del parque por los visitantes, el 35,4 \% de los encuestados lo sienten como un lugar de ocio y recreo, el 31,1 \% resaltan su patrimonio natural, el 18, 9 \% el histórico y monumental y el $12 \%$ el cultural. Así resulta que la valoración del patrimonio natural supera a la suma de las correspondientes a monumentos y actividades culturales.

Sorprende gratamente que algunos encuestados lo consideren un espacio que engloba todos los aspectos, idea que ha presidido la realización de este trabajo.

\section{Conclusiones}

La reciente presentación del parque de El Retiro y de su entorno urbano y monumental colindante, como candidatura a la lista del Patrimonio Mundial de la UNESCO, es circunstancia merecedora del análisis y valoración de dicho patrimonio abordados por este trabajo.

El Retiro presenta un patrimonio heterogéneo, característico de un jardín histórico, donde lo natural manejado por la intervención humana, forma parte de la cultura, de igual manera que los monumentos, esculturas y bienes de ornato en general.

$\mathrm{El}$ aspecto más valorado por los visitantes es la belleza del entorno y la integración en el mismo de los conjuntos escultóricos y arquitectónicos; aunque el conocimiento de la historia de estos últimos no alcanza el nivel que merecerían, que además podría proporcionar un mayor disfrute al visitante. 
El Retiro es también un lugar de encuentro de culturas, tal como se desprende de su historia, de la procedencia actual de sus visitantes y de algunas manifestaciones culturales que se realizan en su interior.

El trabajo de campo muestra como el patrimonio y su conservación están estrechamente relacionados con el turismo y el uso ciudadano, donde el visitante que conoce y valora el recurso, lo divulga y hace posible que perdure. En esta interacción patrimonio-visitantes, también se ha podido detectar algunos problemas relacionados con la gestión del parque y con su uso.

En relación con el mantenimiento y gestión del parque, cabe mencionar las dificultades inherentes a la dispersión y reparto de competencias entre diferentes empresas privadas y las administraciones del Estado y municipal, provocando ausencias de iniciativas y tareas necesarias, en ocasiones urgentes, para dicho mantenimiento. Una tarea compleja dada la diversidad de especies vegetales con necesarios cuidados específicos, o las interacciones con el patrimonio monumental producidas por el desarrollo del arbolado, y más aún las derivadas de la gran afluencia de público en algunas áreas; todo lo cual hace necesario un seguimiento constante.

En lo referente a la información, tanto sobre el patrimonio cultural y natural como de las actividades que se realizan en el parque, resulta evidente una falta de centralización de aquella, tanto en centros de información como de forma virtual. Deficiencias que se traducen en la infrautilización de los recursos del parque.

Como es bastante habitual en la geografía hispana, rica en patrimonio, en una visita a El Retiro también se puede sentir la ausencia de una mayor enfatización y realce de lo que se está visitando, (pancartas informativas, agentes o empleados en número suficiente, etc.), a la par que una mayor vigilancia y regulación de la afluencia de público en fechas señaladas; no ya por la salvaguarda del patrimonio, también por el propio visitante y la calidad de su visita o experiencia.

En definitiva, cabe la satisfacción colectiva por la pervivencia y vistosidad que ha mantenido este espacio a lo largo de la historia. También la gratitud hacia todos los que lo han hecho y lo hacen posible. No obstante, tras las épocas anteriores en las que fue de uso exclusivo de la realeza y después de 152 años de uso público, hoy estamos frente a una evidente masificación, especialmente en días señalados. En suma, esta nueva situación solo será sostenible con medios materiales y humanos adecuados y suficientes.

\section{Agradecimientos}

Agradecemos a siguientes personas relacionadas con el parque la realización de las correspondientes entrevistas:

- Técnico en Jardines Históricos de la Comunidad de Madrid (que ha preferido mantener su anonimato)

- Laura Harguindey, coordinadora de La Cabaña de El Retiro, y Educadora Ambiental

- Iván Ramos, encargado de rutas en La Cabaña de El Retiro.

- Ignacio Bazarra Rodríguez, Asociación Amigos de los Jardines del Buen Retiro.

\section{Bibliografía}

Aguinaga López, E. de (2011). Las puertas del Retiro. En Instituto de Estudios Madrileños, El parque del Buen Retiro. (345-360). Madrid: Instituto de Estudios Madrileños, CSIC.

Aparisi Laporta, L.M. (2011a). La Casa de Fieras. En Instituto de Estudios Madrileños, El parque del Buen Retiro. (377-410). Madrid: Instituto de Estudios Madrileños, CSIC.

Aparisi Laporta, L.M. (2011b). Esculturas y otros elementos ornamentales. En Instituto de Estudios Madrileños, El parque del Buen Retiro. (15-50). Madrid: Instituto de Estudios Madrileños, CSIC.

Aram, F.; Solgi, E.; Higueras García, E.; Mosavi, A. \& Várkonyi-Kóczy, A. R. (2019). The Cooling Effect of Large-Scale Urban Parks on Surrounding Area Thermal Comfort. Energies 2019, 12, 3904, 1-21. https:// doi.org/10.3390/en12203904

Ayuntamiento de Madrid (2016a). Plan Director del Arbolado de Los Jardines del Buen Retiro. Resumen Ejecutivo. https://www.madrid.es/UnidadesDescentralizadas/Agua/PlanRetiro/ResumenEjecutivo_PDArboladoRetiro.pdf

Ayuntamiento de Madrid (2016b). Parques Históricos de Madrid: Jardines de El Buen Retiro. [APP] Disponible en appstore o googleplay.

Ayuntamiento de Madrid (2019a). Arbolado parques históricos, singulares y forestales actualizado en 2019. [Base de datos del arbolado en parques y zonas verdes de Madrid]. https://datos.madrid.es/portal/site/ egob/menuitem.c05c1f754a33a9fbe4b2e4b284f1a5a0/?vgnextoid=0101507f09436610VgnVCM2000001f 4a900aRCRD\&vgnextchannel=374512b9ace9f310VgnVCM100000171f5a0aRCRD\&vgnextfmt=default 
Ayuntamiento de Madrid (2019b). Monumentos de la ciudad de Madrid. [Base de datos]. https://datos. madrid.es/portal/site/egob/menuitem.c05c1f754a33a9fbe4b2e4b284f1a5a0/?vgnextoid=eb8e993ae32 2b610VgnVCM1000001d4a900aRCRD\&vgnextchannel=374512b9ace9f310VgnVCM100000171f5a0aR CRD\&vgnextfmt $=$ default

Ayuntamiento de Madrid (2019c). Monumentos y Edificios Singulares [Base de datos]. https://patrimonioypaisaje.madrid.es/portales/monumenta/es/Monumentos-y-Edificios-Singulares/

Ayuntamiento de Madrid (2019d). Teatro de Títeres [Web]. https://teatrotiteresretiro.es/

Brown J. \& Elliot, J. H. (2016). Un palacio para el rey. El Buen Retiro y la corte de Felipe IV, Taurus (Reedición actualizada y ampliada; $1^{a}$ ed. inglesa 1980).

Cabello Carro, P. (2014). Del Patrimonio de la Corona hasta el actual Patrimonio Nacional (1819-1950). Patrimonio Cultural y Derecho, $N^{o} 18$, pp. 249-288.

Carlos Peña, A. de (2011) El monumento de Alfonso XII en El Retiro. En Instituto de Estudios Madrileños, El parque del Buen Retiro. (15-50). Madrid: Instituto de Estudios Madrileños, CSIC.

Cayetano Martín, M.C. (2011). El Retiro “municipal” en el siglo XIX. En Instituto de Estudios Madrileños, El parque del Buen Retiro. (181-207). Madrid: Instituto de Estudios Madrileños, CSIC.

Comunidad de Madrid (2013). Catálogo Regional de Especies Amenazadas de Fauna y Silvestres, y de Árboles Singulares. Guías de la Naturaleza. Consejería de Medio Ambiente, Ordenación del Territorio y Sostenibilidad. http://www.madrid.org/bvirtual/BVCM003442.pdf

Decreto 18/1992, de 26 de marzo, por el que se aprueba el Catálogo Regional de Especies Amenazadas de Fauna y Flora Silvestres y se crea la categoría de árboles singulares. Boletín Oficial de la Comunidad de Madrid, 85, de 09 de abril de 1992, pp 5-11. http://www.madrid.org/rlma_web/html/web/FichaNormativa. icm?ID $=654 \#$

Domínguez Díez, R. (2019). El arroyo de la Castellana: origen del paseo del Prado, Recoletos y Castellana. Madrid Histórico, $\mathrm{N}^{\circ} .82,76-81$.

Durán Cermeño, C. (2002). Jardines del Buen Retiro. Ediciones Doce Calles.

Feria del Libro (2020). Feria del Libro de Madrid. http://www.ferialibromadrid.com/wp-content/uploads/2019/10/ Dossier_de_patrocinio_de_la_feria_libro_madrid.pdf

Flórez Asencio, M. A. (1998). El Coliseo del Buen Retiro en el siglo XVII: teatro público y cortesano. En Anales de historia del arte Vol. 8, 171-196.

García Fernández, J. (2007). "La regulación y la gestión del Patrimonio Histórico-Artístico durante la Segunda República (1931-1939)". e-rph, $\mathrm{n}^{\circ}$ 1, 1-46. Revista electrónica de protección del patrimonio. http://www. revistadepa-trimonio.es/revistas/numero1/legislacion/estudios/articulo.php.

García Gómez, L. (2017). El Retiro paso a paso: guía del parque. Naperma ediciones.

Gómez-Moreno, F.J.; Artíñano, B.; Díaz Ramiro, E.; Barreiro, M.; Núñez, L.; Coz, E.; Dimitroulopoulou, C.; Vardoulakis, S.; Yagüe, C.; Maqueda, G.; Sastre, M.; Román-Cascón, C.; Santamaría, J.M. \& Borge R. (2019). "Urban vegetation and particle air pollution: Experimental campaigns in a traffic hotspot". Environmental Pollution 247, 195-205. DOI: 10.1016/j.envpol.2019.01.016.

Mariblanca Caneyro, R. (1991). El Retiro, sus orígenes y todo lo demás (1460-1988). Ayuntamiento de Madrid, Junta Municipal de Retiro.

Mariblanca Caneyro, R. (2008). Historia del Buen Retiro. Ediciones La Librería.

Museo Nacional Centro de Arte Reina Sofía (2020). El Museo Reina Sofía aumenta un 12\% los visitantes en 2019. https://www.museoreinasofia.es/sites/default/files/notas-de-prensa/nota_visitantes_2019_reina_sofia.pdf

Museo Nacional del Prado (2020). Datos de visitas. https://www.museodelprado.es/museo/datos-visitas

Orden 68/2015, de 20 de enero, de la Consejería de Medio Ambiente y Ordenación del Territorio, por la que se modifica el Catálogo Regional de Especies Amenazadas de Fauna y Flora Silvestres de la Comunidad de Madrid, en su categoría de "Árboles Singulares". Boletín Oficial de la Comunidad de Madrid, 29, 4 de febrero de 2015, pp 53-58. https://www.bocm.es/boletin/CM_Orden_BOCM/2015/02/04/BOCM-20150204-8.PDF

Palomar Anguas, M.P. (2019). La protección del patrimonio: Iniciativas a nivel mundial y el caso de España. En La protección del patrimonio y su uso turístico (pp. 13-48). Dykinson.

Simón Palmer, $\mathrm{M}^{\mathrm{a}}$ C. (1991). El Retiro, parque de Madrid. Ediciones La Librería.

UNESCO (1972). Convención para la protección del patrimonio mundial, cultural y natural, Aprobada en París el 21 de noviembre de 1972. http://whc.unesco.org/archive/convention-es.pdf

\section{Notas}

Entre febrero y noviembre de 2019.

La encuesta se realizó durante una semana en febrero de 2019, tanto de forma presencial - en horas de mañana y tarde, en días laborables y del fin de semana - como online en redes sociales. Para ello, la segunda de las coautoras contó con la colaboración de la asociación cultural AEGEE, de los trabajadores de la Cabaña de El Retiro y los educadores ambientales del CREAS de Pozuelo de Alarcón. Así se obtuvo una muestra con tamaño y representatividad aceptables. 
3 En la actualidad España es el tercer país, tras Italia (54) y China (53), con 48 bienes inscritos.

4 Con el exilio de Isabel II en 1868, el Gobierno Provisional del Sexenio Revolucionario dictó un Decreto creando el Consejo encargado de la "custodia, conservación y administración de los bienes que constituyeron la Corona de España", que entre otros incluía el Real Sitio del Buen Retiro. A los pocos días dicho Consejo entregó este Real Sitio al Ayuntamiento de Madrid, ya como parque de recreo. "El 26 de junio de 1876 una nueva Ley restituyó a la Corona los bienes incautados en 1869 por el original y pactado procedimiento de dar por válidos los bienes que figuraban en la Ley de 1865, con excepción los que han sido enajenados ó dedicados a servicios públicos"(Cabello, 2014).

5 En 1935, por la Orden de 8 de febrero de 1935 publicada en la Gaceta de Madrid, núm. 47, de 16 de febrero de 1935 se declaró Jardín Artístico el del Buen Retiro (García, 2007).

6 Con la Ley 16/1985, de 25 de junio, del Patrimonio Histórico Español.

$7 \quad$ El expediente se presentó ante la Unesco a comienzos de 2019, para su estudio y evaluación por el Comité de Patrimonio Mundial en julio de 2020. Ya en 2015 el Parque de El Retiro había sido incluido en la Lista Indicativa de la UNESCO, con la denominación "Sitio del Retiro y el Pardo en Madrid", requisito previo para poder presentar su candidatura formal.

8 Municipal, autonómica y estatal.

9 Con Felipe II ya se menciona la existencia de un lago y canales naturales, que posteriormente (Felipe IV y Felipe V) fue transformado en el estanque grande de hoy.

10 Durante el reinado de los Reyes Católicos este monasterio se situaba en la ribera del río Manzanares, por ello un lugar menos salubre que el nuevo emplazamiento, donde fue reconstruido según el estilo gótico tardío.

11 Solo permanecen del mismo el Casón del Buen Retiro, que fue salón de baile y representaciones teatrales, y el Salón de Reinos, estancia destinada a recepciones y actos oficiales y posteriormente sede del museo del ejército, hasta el traslado de este al Alcázar de Toledo. Ambos edificios forman parte de la actual ampliación del museo del Prado.

12 La primera colección de animales salvajes se localizó en las inmediaciones del Real Gabinete de Historia Natural, ya con Carlos III; pero el olor poco soportable y su ubicación junto al Paseo del Prado motivó su traslado al extremo más alejado del parque.

13 Una descripción detallada del patrimonio cultural relativo a monumentos, esculturas y ornato general del parque, es la realizada por Aparisi (2011b).

14 En el Archivo Real de Palacio, en los fondos de Administraciones Patrimoniales, Sección Buen Retiro, expediente 11760.5, se pueden encontrar distintos documentos sobre los viajes en globo en el jardín histórico. Así, el 17 de agosto de 1792 Vicente Lunardi pide permiso real para realizar la primera ascensión en globo aerostático en los jardines del Retiro. Voló durante casi una hora hasta Daganzo, cerca de Alcalá de Henares.

15 También en el mismo archivo y sección anteriores, con expediente 10687.58, se puede encontrar el programa de festejos y combates navales durante el reinado de Isabel II, con descripción detallada de los elementos necesarios para ellos.

16 En el siglo XX se llegaron a contabilizar 20.000 visitantes en un solo día. Fue el Zoo de Madrid hasta 1972, cuando se trasladó a las instalaciones de Batán. En la actualidad, sus instalaciones albergan la biblioteca Eugenio de Trías.

17 La instalación realizada por este monarca, fue conocida como la Leonera, al igual que la debida a Felipe IV, situándose en el lado oriental del parque.

18 No existen datos oficiales sobre el perfil y las motivaciones de los usuarios del parque. Sí estimaciones de su número a partir del contaje de visitantes al Palacio de Cristal., que en 2019 se acercó a los dos millones. Para paliar esta falta de información se ha realizado la encuesta, ya mencionada anteriormente en la metodología del trabajo.

19 Durante 2019 el Museo Nacional Centro de Arte Reina Sofía recibió un total de 4.425 .699 visitantes: 1.714 .049 corresponden a la sede principal, 1.994. 979 al Palacio de Cristal, y 716.671 al de Velázquez (Museo Reina Sofía, 2020). Ese mismo año, el Museo del Prado tuvo 3.203.417 visitas (Museo del Prado, 2020). 